\title{
Upregulation of Anandamide Hydrolysis in the Basolateral Complex of Amygdala Reduces Fear Memory Expression and Indices of Stress and Anxiety
}

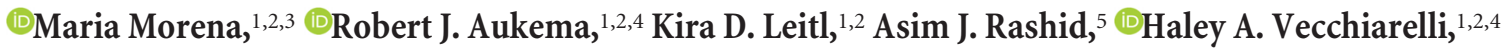 \\ Sheena A. Josselyn, ${ }^{5}$ and Matthew N. Hill ${ }^{1,2,3}$ \\ ${ }^{1}$ Hotchkiss Brain Institute, ${ }^{2}$ Mathison Centre for Mental Health Research, ${ }^{3}$ Departments of Cell Biology and Anatomy and Psychiatry, ${ }^{4}$ Neuroscicence \\ Program, Cumming School of Medicine, University of Calgary, T2N 4N1 Calgary, Alberta, Canada, and ${ }^{5}$ Hospital for Sick Children and Departments of \\ Psychology and Physiology, University of Toronto, M5G 1X8 Toronto, Ontario, Canada
}

Increased anandamide (AEA) signaling through inhibition of its catabolic enzyme fatty acid amide hydrolase (FAAH) in the basolateral complex of amygdala (BLA) is thought to buffer against the effects of stress and reduces behavioral signs of anxiety and fear. However, examining the role of AEA signaling in stress, anxiety, and fear through pharmacological depletion has been challenging due to the redundant complexity of its biosynthesis and the lack of a pharmacological synthesis inhibitor. We developed a herpes simplex viral vector to rapidly yet transiently overexpress FAAH specifically within the BLA to assess the impact of suppressing AEA signaling on stress, fear, and anxiety in male rats. Surprisingly, FAAH overexpression in BLA dampened stress-induced corticosterone release, reduced anxiety-like behaviors, and decreased conditioned fear expression. Interestingly, depleting AEA signaling in the BLA did not prevent fear conditioning itself or fear reinstatement. These effects were specific to the overexpression of FAAH because they were reversed by intra-BLA administration of an FAAH inhibitor. Moreover, the fear-suppressive effects of FAAH overexpression were also mitigated by intra-BLA administration of a low dose of a $\mathrm{GABA}_{\mathrm{A}}$ receptor antagonist, but not an NMDA/AMPA/kainate receptor antagonist, suggesting that they were mediated by an increase in GABAergic neurotransmission. Our data suggest that a permissive AEA tone within the BLA might gate GABA release and that loss of this tone through elevated AEA hydrolysis increases inhibition in the BLA, which in turn reduces stress, anxiety, and fear. These data provide new insights on the mechanisms by which amygdalar endocannabinoid signaling regulates emotional behavior.

Key words: anandamide; anxiety; basolateral amygdala; endocannabinoid; fear conditioning; fear memory

\section{Significance Statement}

Amygdala endocannabinoid signaling is involved in the regulation of stress, anxiety, and fear. Our data indicate that viralmediated augmentation of anandamide hydrolysis within the basolateral amygdala reduces behavioral indices of stress, anxiety, and conditioned fear expression. These same effects have been previously documented with inhibition of anandamide hydrolysis in the same brain region. Our results indicate that the ability of anandamide signaling to regulate emotional behavior is nonlinear and may involve actions at distinct neuronal populations, which could be influenced by the basal level of anandamide. Modulation of anandamide signaling is a current clinical therapeutic target for stress-related psychiatric illnesses, so these data underscore the importance of fully understanding the mechanisms by which anandamide signaling regulates amygdala-dependent changes in emotionality.

\section{Introduction}

Endocannabinoid signaling is involved in the modulation of physiological and behavioral outcomes of stress exposure, in-

Received Aug. 31, 2018; revised Dec. 9, 2018; accepted Dec. 14, 2018.

Author contributions: S.A.J. edited the paper; M.M. and M.N.H. designed research; M.M., R.J.A., K.D.L., and H.A.V. performed research; A.J.R. and S.A.J. contributed unpublished reagents/analytic tools; M.M. and R.J.A. analyzed data; M.M. and M.N.H. wrote the paper. cluding neuroendocrine responses, anxiety, and fear memory processes (Lutz et al., 2015; Hillard et al., 2016; Morena et al.,

This work was supported by the Canadian Institutes of Health Research (CIHR) (M.N.H. and S.A.J.) and Brain Canada (M.N.H.). M.M. received salary support from Alberta Innovates Health Solutions (AIHS) and CIHR postdoctoral fellowships. R.J.A. received salary support from the Mathison Centre for Mental Health Research and Education. K.D.L. was the recipient of a studentship from the Branch Out Neurological Foundation (BONF). H.A.V. received salary support from AIHS and BONF and a Vanier Scholarship from CIHR. We thank Dr. Carsten Wotjak for his valuable input throughout these studies and Min Qiao for technical assistance. 
2016b). The endocannabinoid system consists of cannabinoid type- 1 and type- 2 receptors (CB1R and $\mathrm{CB} 2 \mathrm{R}$ ) and two endogenous ligands, $\mathrm{N}$-arachidonylethanolamide (anandamide; AEA) and 2-arachidonoylglycerol (2-AG). CB1Rs are primarily localized to axon terminals and their activation leads to a transient or sustained suppression of neurotransmitter release from presynaptic neurons, which regulates basal synaptic transmission and many forms of synaptic plasticity (Katona and Freund, 2012; Colangeli et al., 2017). AEA and 2-AG signaling is mainly terminated by hydrolytic degradation by fatty acid amide hydrolase (FAAH) and monoacylglycerol lipase (MAGL), respectively (Blankman and Cravatt, 2013).

Within the basolateral amygdala (BLA), AEA signaling has been implicated in the regulation of stress response, anxiety, and emotional memory (Ganon-Elazar and Akirav, 2009; Hill et al., 2009; Dono and Currie, 2012; Bedse et al., 2015; Gray et al., 2015; Morena et al., 2016a; for review, see Ramikie and Patel, 2012; Gunduz-Cinar et al., 2013a; Morena et al., 2016b). Acute stress exposure rapidly reduces AEA signaling in the BLA through increased AEA hydrolysis by FAAH (Patel et al., 2005; Rademacher et al., 2008; Hill et al., 2009; Gray et al., 2015; Jenniches et al., 2016). This loss of AEA signaling is thought to occur primarily at CB1Rs on glutamatergic inputs to the BLA, which in turn disinhibits afferent excitatory drive and contributes to the activation of BLA output pyramidal neurons, thus recruiting downstream circuits to orchestrate different aspects of stress response, including hypothalamic-pituitary-adrenal (HPA) axis activation, increased anxiety, and cognitive alterations (Gray et al., 2015; Morena et al., 2016b). Consistently, increased AEA signaling through genetic deletion or pharmacological inhibition of FAAH systemically or directly into the BLA mitigates neuroendocrine and behavioral responses to stress (Kathuria et al., 2003; Bambico et al., 2010; Morena et al., 2016a).

Many studies have highlighted the relevance of AEA signaling in fear memory regulation (for reviews, see Morena and Campolongo, 2014; Lutz et al., 2015; Morena et al., 2016b). Marsicano et al., 2002 and subsequent investigators (Gunduz-Cinar et al., 2013b) demonstrated the involvement of AEA signaling in conditioned fear expression and extinction, showing that presentation of a tone previously paired with aversive footshock during extinction trials elevates AEA levels in the BLA. Consistently, pharmacologically induced increases in AEA levels by FAAH inhibition systemically or directly in the BLA reduces conditionedfear response both acutely (Llorente-Berzal et al., 2015) and over the following day facilitating fear extinction (Chhatwal et al., 2005; Bitencourt et al., 2008; Pamplona et al., 2008; GunduzCinar et al., 2013b). Similarly, humans and mice carrying the C385A polymorphism in FAAH, which exhibit reduced expression and functionality of FAAH and thus elevated AEA levels, present reduced anxiety, increased fear extinction, and blunted activation of the amygdala (Hariri et al., 2009; Gunduz-Cinar et al., 2013b; Dincheva et al., 2015; Mayo et al., 2018).

Despite this extensive literature, the explicit delineation of the necessity of BLA AEA signaling to regulate these stress-related physiological and behavioral responses have not been clearly elucidated. This is partly due to the fact that it has not been possible

M.N.H. has performed scientific consultation for Pfizer. The remaining authors declare no competing financial interests. Funding agencies had no influence on the design, execution, or publishing of this work.

Correspondence should be addressed to Matthew N. Hill at mnhill@ucalgary.ca or Maria Morena at mmorena@ucalgary.ca.

https://doi.org/10.1523/JNEUROSCI.2251-18.2018

Copyright $\odot 2019$ the authors $\quad 0270-6474 / 19 / 391276-18 \$ 15.00 / 0$ to date to produce a depletion of AEA as its biosynthesis is complex and seems to involve redundant pathways (Blankman and Cravatt, 2013). Unlike 2-AG, which can be readily depleted through genetic or pharmacological inhibition of its biosynthetic enzyme diacylglycerol lipase (Shonesy et al., 2014; Ogasawara et al., 2016; Bedse et al., 2017), sufficiency studies of AEA depletion have been challenging. However, AEA degradation is almost entirely mediated by FAAH, which determines AEA concentration at active synapses (Blankman and Cravatt, 2013). Therefore, to investigate the role of AEA signaling in the regulation of stressrelated responses, we augmented AEA hydrolysis through viralmediated FAAH overexpression in BLA principal neurons and examined the impact that AEA depletion had on stress-induced neuroendocrine response, anxiety, and fear memory dynamics in rats.

\section{Materials and Methods}

\section{Animals}

Male Sprague Dawley rats (300-375 g at the time of behavioral experiments; Charles River Laboratories) were pair housed in a temperaturecontrolled $\left(20 \pm 1{ }^{\circ} \mathrm{C}\right)$ vivarium room and maintained under a $12 \mathrm{~h} / 12 \mathrm{~h}$ light/dark cycle (8:00 A.M. to 8:00 P.M. lights on). Food and water were available ad libitum. All tests were performed during the light phase of the cycle between 10:00 A.M. and 5:00 P.M. All experimental procedures were in compliance with protocols approved by the University of Calgary Animal Care Committee and guidelines from the Canadian Council on Animal Care. All efforts were made to minimize animal suffering and to reduce the number of animals used.

\section{Viral construct}

The coding region of FAAH was isolated by PCR amplification from mouse brain cDNA (forward primer: $5^{\prime}$ ggtcggaagcttgccaccatggtgctgagcgaagtgtg $3^{\prime}$, reverse primer: $5^{\prime}$ gcagatggcggccgctcaagatggccgcttttc $\left.3^{\prime}\right)$. Using restriction sites engineered into the primers (HindIII and NotI, respectively), the isolated cDNA was subcloned into a bicistronic pHSV (herpes simplex virus)-p1005+ amplicon vector after the HSV-derived IE $4 / 5$ promoter. A second promoter in this plasmid, cytomegalovirus (CMV), drove expression of green fluorescent protein (GFP). Replication-deficient HSV-derived particles were made from this vector as previously described (Han et al., 2009). The control virus, HSV-GFP, was identical to the HSV-GFP-FAAH with the FAAH gene excluded. Both viruses (HSV-GFP and HSV-GFP-FAAH) had titers $4.0 \times 10^{7}$ infectious units/ml. Maximal gene expression following HSV infusion occurs within $24-72 \mathrm{~h}$ and rapidly dissipates within $6-7 \mathrm{~d}$ after injection (Carlezon et al., 1997; Barrot et al., 2002).

\section{Drugs}

The AEA hydrolysis inhibitor URB597 (10 ng; Cayman Chemical), the $\mathrm{GABA}_{\mathrm{A}}$ antagonist (-)-bicuculline methiodide (BIC; $50 \mathrm{ng}$; Tocris Bioscience), the NMDA receptor antagonist D-AP5 (5 $\mu \mathrm{g}$; Tocris Bioscience), the AMPA/kainate receptor antagonist DNQX (1 $\mu \mathrm{g}$; Tocris Bioscience) or their vehicles (5\% DMSO, 5\% Tween $80,90 \%$ saline for D-AP5 and DNQX and 5\% polyethylene glycol, 5\% Tween 80, 90\% saline for the remaining experiments) were bilaterally infused into the BLA $(0.2 \mu \mathrm{l} / \mathrm{side})$ over $1 \mathrm{~min}$. The dose of URB597 was chosen based on previously published studies (Morena et al., 2014, 2016a; Gray et al., 2015). For BIC, the $50 \mathrm{ng}$ dose was chosen on the basis of previously published work (Ratano et al., 2014) and pilot experiments performed in our laboratory showing no effects on freezing behavior and memory by itself. For D-AP5 and DNQX, doses were chosen on the basis of previously published work (Barros et al., 2000; Zimmerman and Maren, 2010) and pilot experiments performed in our laboratory. All drug solutions were freshly prepared before each experiment.

Surgery, viral vector, and drug administration

Rats were anesthetized with ketamine hydrochloride $(100 \mathrm{mg} / \mathrm{kg})$ and xylazine $(7 \mathrm{mg} / \mathrm{kg})$, given intraperitoneally. Subsequently, they were injected with $3 \mathrm{ml}$ of saline subcutaneously to facilitate clearance of these 
drugs and prevent dehydration. Animals were then positioned in a stereotaxic frame (David Kopf Instruments) and two glass capillaries were bilaterally lowered into the BLA (coordinates: anteroposterior, -2.8 $\mathrm{mm}$, and mediolateral, $\pm 5.1 \mathrm{~mm}$ from bregma; dorsoventral, $-6.7 \mathrm{~mm}$ from dura) (Paxinos and Watson, 2004). Recombinant HSV type 1 carrying GFP along with FAAH (HSV-GFP-FAAH) and a control virus only carrying GFP (HSV-GFP) were pressure injected with the Nanoject II apparatus (Drummond Scientific) in a total volume of $2 \mu \mathrm{l} /$ side over 2 $\mathrm{min}$ and then the capillaries were left in place for an additional $5 \mathrm{~min}$ to ensure diffusion. The injection volume was chosen based on previous studies using this viral construct (Yiu et al., 2014) and on pilot experiments performed in our laboratory finding that, despite the rather large volume, GFP expression did not spread beyond the BLA and, at lower injection volumes $(0.5,1$, and $1.5 \mu \mathrm{l})$, we were not able to achieve reliable GFP expression, a significant elevation in AEA hydrolysis, or depletion of AEA content within the BLA itself (data not shown).

For the last four experiments, rats received cannula implantation. Stainless-steel guide cannulae (23 gauge, 15-mm-long) were implanted bilaterally with the cannula tips $2 \mathrm{~mm}$ above the BLA (coordinates: anteroposterior, $-2.8 \mathrm{~mm}$ and mediolateral, $\pm 5.0 \mathrm{~mm}$, from bregma; dorsoventral, $-6.5 \mathrm{~mm}$, from skull surface; Paxinos and Watson, 2004). The cannulae were affixed to the skull with two anchoring screws and dental cement. Stylets (15-mm-long 00 insect dissection pins) were inserted into each cannula to prevent clogging.

After surgery, the rats were retained on a heated pad until they recovered from anesthesia and were then returned to their home cages. Following surgical cannula implantation, rats were allowed to recover from surgery for at least 1 week before testing. All animals with surgical implant were also bilaterally injected with the viral construct through their cannulae $(2 \mu \mathrm{l} / \mathrm{side})$. Bilateral infusions of drugs or an equivalent volume of vehicle or HSV into the BLA were made by using a 30-gauge injection needle connected by polyethylene tubing (PE-20) to a $10 \mu \mathrm{l}$ Hamilton microsyringe driven by a minipump (Harvard Apparatus) over a period of $2 \mathrm{~min}$. The injection needle protruded $2 \mathrm{~mm}$ beyond the tip of the cannula (Morena et al., 2014). The injection needles were retained within the cannulae for an additional $20 \mathrm{~s}$ after drug infusion or $5 \mathrm{~min}$ after virus infusion to maximize diffusion and to prevent backflow into the cannulae.

\section{Validation of viral-mediated FAAH overexpression}

Double-immunofluorescence experiment. Seventy-two hours following intra-BLA HSV-GFP or HSV-GFP-FAAH injection, rats were deeply anesthetized with sodium pentobarbital $(100 \mathrm{mg} / \mathrm{kg}$, i.p.) and perfused transcardially with $0.9 \%$ saline followed by ice-cold fixative made of $4 \%$ paraformaldehyde. The brains were then removed and postfixed in a $4 \%$ paraformaldehyde solution overnight at $4^{\circ} \mathrm{C}$. The brains were transferred to a $20 \%$ sucrose solution in saline for cryoprotection. Coronal sections of $35 \mu \mathrm{m}$ were cut on a cryostat, placed in KPBS $0.1 \mathrm{M}$ solution, and stored at $4^{\circ} \mathrm{C}$ until staining.

Free-floating sections were washed in $0.1 \mathrm{M} \mathrm{KPBS}$ and incubated in blocking solution $(0.3 \%$ Triton X-100, 5\% normal goat serum in $0.1 \mathrm{M}$ KPBS) for $2 \mathrm{~h}$ at room temperature before incubating in both primary antibodies (mouse anti-glutamate decarboxylase 67, GAD67, 1:500, Millipore catalog \#MAB5406, RRID:AB_2278725; chicken anti-GFP, 1:1000, Aves Laboratories catalog \#GFP-1020, RRID:AB_10000240) for $48 \mathrm{~h}$ at $4^{\circ} \mathrm{C}$. Slices were then washed in $0.1 \mathrm{M} \mathrm{KPBS}$ and incubated at room temperature for $2 \mathrm{~h}$ in both secondary antibodies (Cy3 goat anti-mouse, 1:1000, Jackson ImmunoResearch Laboratories catalog \#115-165-003, RRID:AB_2338680; Alexa Fluor 488 goat antichicken, 1:1000, Thermo Fisher Scientific catalog \#A-11039, RRID: AB_2534096). Finally, slices were washed in $0.1 \mathrm{~m}$ KPBS, mounted, and coverslipped onto charged slides with Fluoroshield mounting medium (Sigma-Aldricha) for imaging.

Different series of slices from the same animals were immunolabeled for $\alpha \mathrm{Ca}^{2+} /$ calmodulin-dependent protein kinase II (CaMKIIa) and GFP by using a slightly different protocol. Briefly, free-floating sections were washed in PBST (0.05\% Tween 20 in PBS) and heat-mediated antigen retrieval was performed to expose the epitope (Shi et al., 1993; Kanai et al., 1998). Slices were then rewashed in PBST and incubated for $2 \mathrm{~h}$ at room temperature in blocking solution (PBST $+20 \%$ normal goat serum) before incubating in both primary antibodies (mouse antiCaMKIIa, 1:100, Abcam catalog \#ab22609, RRID:AB_447192; chicken anti-GFP, 1:100, Aves Laboratories catalog \#GFP-1020, RRID: $\left.A B \_10000240\right)$ for $72 \mathrm{~h}$ at $4^{\circ} \mathrm{C}$. Slices were then washed in PBST and incubated for $2 \mathrm{~h}$ in both secondary antibodies (Cy3 goat anti-mouse, 1:100, Jackson ImmunoResearch Laboratories catalog \#115-165-003, RRID:AB_2338680; Alexa Fluor 488 goat anti-chicken, 1:500, Thermo Fisher Scientific catalog \#A-11039, RRID:AB_2534096). Finally, slices were washed in PBST, mounted, and coverslipped onto miscroscope slides with Fluoroshield mounting medium (Sigma-Aldrich) for imaging.

Images were taken on a Leica DM5500 Q confocal microscope and displayed and analyzed using LAS X software (version 3.1.1.15751). Settings for laser power, gain, and offset were kept constant for each experiment. All images were taken through a $20 \times$ objective (numerical aperture 0.40$)$ in areas of the BLA expressing high levels of $\mathrm{GFP}^{+}$neurons. Each marker was counted independently before overlaying images to observe colocalization of either GAD67 or CaMKIIa with GFP-labeled cells.

Membrane preparation and FAAH activity assay. Seventy-two hours following intra-BLA HSV-GFP, HSV-GFP-FAAH, or $0.9 \%$ saline solution injection, rats underwent rapid decapitation and the amygdalae were dissected as described previously (Hill et al., 2010; Gray et al., 2015), with tissue extraction focusing on the region of the BLA immediately surrounding the end of the needle track. To ensure that our viral vector itself did not influence FAAH activity and endocannabinoid content, as has been previously reported with a lentiviral vector (Rubino et al., 2008), we included an additional group for these validation studies which included a no HSV, saline-only injection group to act as a baseline for us to compare the HSV-GFP against. Brain samples were stored at $-80^{\circ} \mathrm{C}$. Membranes were collected by homogenization of frozen tissue in 10 volumes of TME buffer (50 mm Tris HCl, pH 7.4, 1 mm EDTA, and $3 \mathrm{~mm}$ $\mathrm{MgCl}_{2}$ ) (Hill et al., 2009; Morena et al., 2015). Homogenates were then centrifuged at $18,000 \times \mathrm{g}$ for $20 \mathrm{~min}$ at $4^{\circ} \mathrm{C}$ and the resulting crude membrane fraction-containing pellet was resuspended in 10 volumes of TME buffer. Protein concentrations were determined using the Bradford method (Bio-Rad Laboratories). FAAH-mediated AEA hydrolysis from amygdala membranes was measured by conversion of AEA labeled with $\left[{ }^{3} \mathrm{H}\right]$ in the ethanolamine portion of the molecule to $\left[{ }^{3} \mathrm{H}\right]$ ethanolamine preparations as reported previously (Hill et al., 2009; Morena et al., 2015). The binding affinity $\left(K_{\mathrm{m}}\right)$ of AEA for FAAH and the maximal hydrolytic activity $\left(V_{\max }\right)$ of FAAH for this conversion were determined by fitting the data to the Michaelis-Menten equation using GraphPad Prism software (RRID:SCR_002798).

Endocannabinoid extraction and analysis. Seventy-two hours following intra-BLA HSV-GFP, HSV-GFP-FAAH, or $0.9 \%$ saline solution injection, rats underwent rapid decapitation and the amygdalae were dissected as described above. Brain samples were stored at $-80^{\circ} \mathrm{C}$ until measurement of endocannabinoid levels. The lipid extraction process was performed as described previously (Qi et al., 2015; Morena et al., 2018). In brief, brain tissue was weighed and placed into borosilicate glass culture tubes containing $2 \mathrm{ml}$ of acetonitrile with 5 pmol d8-AEA and 5 $\mathrm{nmol} \mathrm{d} 8 \mathrm{-2}-\mathrm{AG}$ for extraction and homogenized with a glass rod. Tissue was sonicated for $30 \mathrm{~min}$ on ice water, incubated overnight at $-20^{\circ} \mathrm{C}$ to precipitate proteins, and then centrifuged at $1500 \times g$ to remove particulates. The supernatants were transferred to a new glass tube and evaporated to dryness under $\mathrm{N}_{2}$ gas. The tubes were washed with $300 \mu \mathrm{l}$ of acetonitrile to recapture any lipids adhering to the wall of the tube and evaporated again under $\mathrm{N}_{2}$ gas. Finally, samples were reconstituted in $200 \mu \mathrm{l}$ of acetonitrile and stored at $-80^{\circ} \mathrm{C}$ until analysis. Analysis of AEA and 2-AG was performed by liquid chromatography tandem mass spectrometry analysis as described previously (Qi et al., 2015).

\section{Behavioral testing}

Elevated plus maze. The elevated plus maze apparatus (EPM; Med Associates) comprised two open arms $\left(50 \times 10 \times 75 \mathrm{~cm}^{3} ; 1 \times \mathrm{w} \times \mathrm{h}\right)$ and two closed arms $\left(50 \times 10 \times 75 \mathrm{~cm}^{3} ; 1 \times \mathrm{w} \times \mathrm{h}\right)$ that extended from a common central platform $\left(10 \times 10 \mathrm{~cm}^{2}\right)$. The maze was located within a 
sound-isolated room under dim light conditions (open arms, 15 lux; closed arms, 5 lux). A slightly modified procedure of that we described previously (Manduca et al., 2015; Morena et al., 2016a) was used. Each rat was placed in the central area of the apparatus with the head facing a closed arm. Exposure lasted for $5 \mathrm{~min}$ and the behavior was recorded by using a video camera positioned above the experimental apparatus. A trained observer who was unaware of treatment condition analyzed videos. The following parameters were analyzed as indicators of anxiety-like behavior: percentage time spent in the open arms (\% open time), expressed as [(seconds spent on the open arms of the maze/seconds spent on the open + closed arms $) \times 100]$; percentage open arm entries $(\%$ open entries), expressed as [(number of entries into the open arms/ number of entries into open + closed arms $) \times 100]$, the time to first enter the open arms (latency to first enter open arms, s). The number of entries into the closed arms was considered as an indicator of locomotor activity (Rodgers et al., 1999; Holmes and Rodgers, 2003; Morena et al., 2016a). We also evaluated the total number of head dippings (the rat investigating the area beneath the EPM; HDIPS) and the number of stretch attend postures (posture in which the body is stretched forward then retracted to the original position without any forward locomotion and investigating the environment; SAP). As a measure of exploratory behavior, the number of HDIPS relates more to a reduced level of anxiety-like behavior, whereas the number of SAP indicates a measure of risk assessment and tends to associate positively with anxious behavior (Rodgers et al., 1997, 1999; Bortolato et al., 2006; Morena et al., 2016a). The maze was cleaned with $70 \%$ ethanol solution after each use.

Light-dark ( $L D)$ box. The LD box (Med Associates) was made of white and black opaque Plexiglas $\left(44 \times 22 \times 30 \mathrm{~cm}^{3}, 1 \times \mathrm{w} \times \mathrm{h}\right.$, light chamber, 15 lux; $44 \times 22 \times 30 \mathrm{~cm}^{3}, 1 \times \mathrm{w} \times \mathrm{h}$, dark chamber, 5 lux $)$. The chambers were connected by a $9 \times 10 \mathrm{~cm}^{2}(1 \times \mathrm{h})$ door separating the two chambers. Animals were placed in the dark compartment. The amount of time it took the animal to fully emerge into the light side and the time spent ambulating in the light side were recorded for $10 \mathrm{~min}$ and scored by a trained experimenter blind to the treatment conditions. The behavioral parameters analyzed were as follows: percentage time spent in light compartment (\% light section time), expressed as [(seconds spent in the light chamber/total time, in seconds, spent in the apparatus) $\times 100]$; total number of entries into the light chamber (light section entries, counts); the time to first enter the light chamber (latency to first enter the light section, s); the number of attempts to enter the light chamber (attempts to enter the light section, counts). The apparatus was cleaned with $70 \%$ ethanol solution after each use.

Open-field (OF) apparatus. The testing arena consisted of a wooden cage measuring $90 \times 90 \times 60 \mathrm{~cm}^{3}(1 \times \mathrm{w} \times \mathrm{h})$. The apparatus was located within a sound-isolated room under dim light conditions (17 lux). Each rat was placed in the central area of the OF and allowed to explore the apparatus freely for $10 \mathrm{~min}$. The behavior was recorded by using a video camera positioned above the experimental apparatus and a trained observer who was unaware of treatment condition analyzed videos. The locomotor activity (total distance traveled in meters) was recorded using the software EthoVision XT, RRID:SCR_000441 (Noldus). The following behavioral parameters were analyzed: percentage time spent in center quadrant (\% center time), expressed as [(seconds spent in the center of the apparatus/total time, in seconds, spent in the OF) $\times 100$ ]; total number of entries in the center quadrant of the OF (center entries, counts). Both measures correlate negatively with anxious behavior. Furthermore, we evaluated the exploratory behavior expressed as the sum of the rearing and wall rearing events and other behaviors that positively correlate with anxiety, expressed as the sum of SAP and self-grooming events (anxietylike behaviors) (Kalueff and Tuohimaa, 2005; Morena et al., 2016a). The apparatus was cleaned with $70 \%$ ethanol solution after each use.

Fear-conditioning apparatus. Rats were trained and tested in fearconditioning chambers $\left(30.5 \times 24.1 \times 21 \mathrm{~cm}^{3}, 1 \times \mathrm{w} \times \mathrm{h}\right)$ equipped with metal stainless-steel rod flooring connected to a shock generator. Each chamber was enclosed within ventilated and sound attenuating cubicles (Med Associates). Three different contexts were used (contexts A-C). Context A consisted of a chamber with a grid floor, back and side metal walls, clear Plexiglas front door and ceiling, and white light. Context A was cleaned with $70 \%$ ethanol between rats. To create a novel testing context (context B), the original grid floor was covered by a white opaque plastic insert and the side metal walls were covered by a white plastic panel to create a curved wall. Context B was cleaned with Virkon solution between rats. Context $\mathrm{C}$ consisted of a grid floor and white plastic walls and was cleaned with soapy water between rats. A video camera located on the inner door of the conditioning box recorded video and the resulting output was analyzed for freezing behavior (i.e., absence of movement except for respiration) using Med Associates Video Freeze Software, RRID:SCR_014574).

\section{Experimental design}

Restraint stress experiment and plasma corticosterone assay. On day 1, rats were bilaterally injected into the BLA with the control viral construct, HSV-GFP, or the one containing FAAH, HSV-GFP-FAAH. Rats were allowed to recover from surgery for $72 \mathrm{~h}$ to get the maximal viral expression and, on day 4 , were subjected to a 60 min restraint stress. Restraint was performed by placing the animal into a $22 \times 7 \mathrm{~cm}$ plastic tube with an adjustable plug to accommodate the size of the rat so that the animal was unable to move. Blood samples were collected from a razor nick over the lateral tail vein into ice-chilled, EDTA-treated tubes at different time points: $0,30,60$, and $90 \mathrm{~min}$ from stress onset. Tail blood was centrifuged at $10,000 \mathrm{rpm}$ for $20 \mathrm{~min}$ at $4^{\circ} \mathrm{C}$. Plasma was then stored at $-20^{\circ} \mathrm{C}$ until corticosterone analyses with an ELISA kit (Cayman Chemical) according to the manufacturer's instructions, as described previously (Vecchiarelli et al., 2016). Samples were tested in duplicate and diluted 1:1000 to ensure that corticosterone levels fit on the linear portion of the standard curve. The detection limit of the assay was $30 \mathrm{pg} / \mathrm{ml}$ at $80 \%$ binding.

Anxiety experiments. To examine the anxiety trait in condition of AEA depletion and to reduce the total number of animals being used, we performed a behavioral battery of anxiety tests. To reduce any possible bias relative to performing a battery of behavioral tests, we kept handling procedures, housing conditions, and behavioral test procedures consistent across HSV-GFP control rats and HSV-GFP-FAAH rats. On day 1, both groups of animals were handled for 1 min each and $24 \mathrm{~h}$ later (day 2) were divided into 2 experimental groups and injected with either the HSV-GFP or HSV-GFP-FAAH constructs. Animals were handled again on day 3. Anxiety tests occurred on days 4 and 5, when the viral expression was maximal. On day 4, rats underwent a 5 min EPM test; on day 5, they were subjected to a $10 \mathrm{~min} \mathrm{LD}$ box test and, immediately afterward, rats were placed in an OF arena for $10 \mathrm{~min}$. Throughout the experimental procedures, rats were housed in a room adjacent to the rooms where behavioral experiments were conducted. To reduce any bias related to the habituation to the experimental room, the three behavioral tasks were conducted in three different rooms and each rat was individually tested in each room.

Auditory fear-conditioning experiments. Separate cohorts of animals were used for each of the following experiments. Because our intent in these experiments was to examine the impact of FAAH overexpression on fear extinction, the conditioning arm of all studies (except for one experiment) was performed before viral injection and thus was done in the absence of any manipulation. To habituate the animals to the behavioral testing room, rats were transferred to the behavioral room and their home cage was placed in sound-attenuating, ventilated, and lighted cabinets for at least $30 \mathrm{~min}$ before and after the handling on days 1,2 , and 3 and for $90 \mathrm{~min}$ before and after testing the following days. Rats were handled for 1 min each. On day 2 and 3, immediately after the handling procedure, animals were habituated to the experimental chambers for 10 min. Auditory fear conditioning (day 4) was performed in context A. After a 5 min acclimation period, all rats were exposed to 3 conditioning trials. Each conditioning trial involved presentation of the conditioned stimulus (CS; $80 \mathrm{~dB}, 4 \mathrm{~Hz}$ tone) for $30 \mathrm{~s}$, co-terminating with a $1 \mathrm{~s}$ unconditioned stimulus (US; $0.65 \mathrm{~mA}$ shock, for rats undergone fear conditioning in naive conditions and that received surgery microinjections the day after fear conditioning; $1.3 \mathrm{~mA}$ shock, for rats undergone surgery for either virus microinjections or cannula implantation before fear conditioning). The two different shock intensities were used to ensure comparable levels of memory in all experimental control groups (Morena et al., 2014; Park et al., 2016). Intertrial interval (ITI) between two consecutive CS-US pairings was $3 \mathrm{~min}$. After conditioning, each rat 
was returned to its home cage. To prevent any influence of anesthetic or surgery on the consolidation of the initial fear memory, we waited for $24 \mathrm{~h}$ following fear conditioning before we performed intra-BLA administration of the viral vector. Twenty-four hours after conditioning, rats were injected with HSV-GFP or HSV-GFP-FAAH (day 5; as described above) and were allowed to recover from surgery for $72 \mathrm{~h}$. On day 8 , when the viral expression was maximal, rats received an extinction training session consisting of 20 CS presentations with an ITI between CSs of 2 $\mathrm{min}$, in context $\mathrm{B}$. On days $9-11$, rats received 3 consecutive days of extinction retrieval trials in context B. After a 2 min acclimation period, rats were presented with 5 CSs ( 2 min ITI). A separate cohort of rats underwent surgical injection of the viral constructs $72 \mathrm{~h}$ before fear conditioning (day 1) to evaluate the effects on fear memory acquisition.

Additional pharmacological studies were performed on separate groups of animals and, for all of these studies, rats were implanted with bilateral cannulae in the BLA 7-10 d before the auditory fearconditioning experiments. They were exposed to the same fearconditioning procedure as described above except for day 5 , when they were injected with the viral constructs through their cannulae as opposed to directly through a cranial burr hole. On day 8 , separate cohorts of animals were administered the FAAH inhibitor URB597, the GABA $_{\mathrm{A}}$ receptor antagonist $\mathrm{BIC}$, or a mixture of the NMDA receptor antagonist $\mathrm{D}$-AP5 together with the AMPA/kainate receptor antagonist DNQX directly in to the BLA $60 \mathrm{~min}$ before fear memory retrieval/extinction training. Additionally, after the last extinction retrieval session, animals received a reinstatement session on day 12 and, $24 \mathrm{~h}$ later, a test for fear reinstatement (day 13). During the reinstatement session, rats received 4 unsignaled foot shocks (1.3 mA, $1 \mathrm{~s} ; 2$ min ITI) in context C. The next day, they were tested for fear reinstatement assessed by their freezing to the tone alone (Context B, 5 CS presentations, 2 min ITI).

\section{Histology}

To check for cannula placement, after the behavioral experiments, rats were anesthetized with an overdose of sodium pentobarbital $(100 \mathrm{mg} / \mathrm{kg}$, i.p.) and perfused transcardially with $0.9 \%$ saline. The brains were then removed and immersed in a $4 \%$ paraformaldehyde solution. At least $48 \mathrm{~h}$ before sectioning, the brains were transferred to a $20 \%$ sucrose solution in saline for cryoprotection. Coronal sections of $35 \mu \mathrm{m}$ were cut on a cryostat, mounted on charged slides, and stained with Cresyl violet. The sections were examined under a light microscope (Leica DM4000 B LED) and determination of the location of infusion needle tips within the BLA was made according to the standardized atlas plates of Paxinos and Watson (2004) by an observer blinded to treatment condition.

\section{Statistical analysis}

All data are expressed as mean \pm SEM. Data obtained from testing for anxiety-like behavior and the magnitude of the total plasma corticosterone stress response were analyzed with unpaired Student's $t$ tests. Oneway ANOVA followed by Bonferroni post hoc multiple-comparisons tests were used to analyze FAAH activity and AEA and 2-AG levels. Two-way ANOVA was used to analyze freezing levels at extinction retrieval sessions 2 and 3. Repeated-measures ANOVA followed by Bonferroni post hoc multiple-comparisons tests were used to analyze the remaining auditory fear-conditioning behavioral data and the plasma corticosterone time course. Percentage of freezing during extinction training sessions were averaged in 4 blocks of 5 consecutive CSs each (CS $1-5$, CS $6-10$, CS 11-15, CS 16-20) for extinction retrieval 2 and 3 and test for reinstatement percentage of freezing during the 5 CS presentations was averaged. A probability level of $<0.05$ was accepted as statistically significant. The numbers of rats per group are indicated in the figure legends.

\section{Results \\ Anatomical localization and functional characterization of FAAH overexpression in the BLA}

To phenotype the type of BLA cells infected by HSV, we bilaterally microinjected rats with the HSV vector, waited for $72 \mathrm{~h}$ to allow maximal expression (Fig. 1A,B), and performed doublelabeling immunohistochemistry for GFP and either CaMKIIa as a marker of excitatory pyramidal neurons or GAD67 as a marker of inhibitory neurons. We observed that HSV primarily (82.99\%) infected pyramidal excitatory neurons (CaMKIIa + ) in the BLA (Fig. $1 C, E, F, G)$, with only a very small number $(1.68 \%)$ of $\mathrm{GFP}^{+}$ infected neurons colabeling with GAD67 (Fig. $1 D, H, I, J$ ). Therefore, consistent with previous studies showing also that HSV is neurotropic (Cole et al., 2012; Yiu et al., 2014), we found that HSV predominantly infects pyramidal excitatory neurons in the BLA. Because FAAH expression in the BLA is found primarily only within large pyramidal neurons (Gulyas et al., 2004), this indicates that our approach did not result in ectopic expression of FAAH in cells that normally do not express it, but rather that we increased the expression of FAAH within cell types that natively express this enzyme.

To examine the functionality of FAAH overexpression in the BLA, separate groups of animals were bilaterally microinjected with $0.9 \%$ saline solution, HSV-GFP, or HSV-GFP-FAAH into the BLA and killed $72 \mathrm{~h}$ later for BLA dissection and subsequent enzymatic FAAH activity analysis and determination of endocannabinoid levels (Fig. 1A). As shown in Figure $1 K$, one-way ANOVA for $V_{\max }$ of FAAH revealed a significant treatment effect $\left(F_{(2,12)}=8.81, p=0.004\right)$. Post hoc comparison indicated that rats injected with HSV-GFP-FAAH presented increased $V_{\max }$ of AEA hydrolysis by FAAH compared with both groups injected with saline $(p<0.05)$ and HSV-GFP $(p<0.01)$, so HSV-GFPFAAH injection successfully induced FAAH overexpression as indicated by increased FAAH hydrolytic activity. Furthermore, post hoc analysis showed no significant difference between salinetreated rats and rats injected with HSV-GFP, which importantly indicates that the HSV viral vector itself did not alter FAAH $V_{\max }$ as has been reported with lentiviral vectors (Rubino et al., 2008). One-way ANOVA for $K_{\mathrm{m}}$ of FAAH did not reveal a significant treatment effect $\left(F_{(2,12)}=2.99, p=0.09 ; K_{\mathrm{m}}\right.$, expressed as mean \pm SEM, $\mu \mathrm{M}$, for saline group: $1.32 \pm 0.25$; HSV-GFP group: $1.51 \pm 0.29$; HSV-GFP-FAAH group: $2.15 \pm 0.20$ ), so FAAH overexpression did not change the affinity of the enzyme for its substrate. One-way ANOVA for AEA levels revealed a significant treatment effect $\left(F_{(2,23)}=7.11, p=0.004\right.$; Fig. $\left.1 L\right)$. Post hoc comparison showed that the HSV-GFP-FAAH group presented decreased AEA levels compared with both the saline ( $p<$ $0.05)$ and HSV-GFP $(p<0.01)$ groups. Again, no significant difference was found between the saline and the HSV-GFP groups, supporting the enzyme activity data showing that the HSV vector itself did not have an impact on FAAH activity or endocannabinoid content. One-way ANOVA for 2-AG levels did not show any significant treatment effect $\left(F_{(2,23)}=0.08, p=0.93\right.$; Fig. $1 M)$. Therefore, FAAH overexpression successfully and selectively reduced AEA and not 2-AG levels and the HSV vector itself did not alter endocannabinoid levels in the BLA.

\section{Intra-BLA FAAH overexpression decreases plasma corticosterone stress response and reduces anxiety-like behavior}

To examine the effects of intra-BLA FAAH overexpression on stress-induced plasma corticosterone response, $72 \mathrm{~h}$ after HSVGFP or HSV-GFP-FAAH microinjection, rats were stressed for $1 \mathrm{~h}$ in a restraint tube and tail blood was collected at time $0,30,60$, and $90 \mathrm{~min}$ from stress onset to measure plasma corticosterone levels (Fig. 2A). As shown in Figure 2B, repeated-measures ANOVA for corticosterone plasma levels showed a significant effect of time $\left(F_{(3,36)}=19.97, p<0.0001\right)$, but no treatment or time $\times$ treatment interaction effect $\left(F_{(1,36)}=1.85, p=0.20\right.$; $\left.F_{(3,36)}=1.85, p=0.16\right)$. To gauge relative effects of treatment on the magnitude of the total plasma corticosterone stress response, 
HSV-GFP

HSV-GFP-FAAH

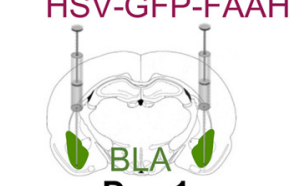

Immunofluorescence

FAAH activity

eCB levels
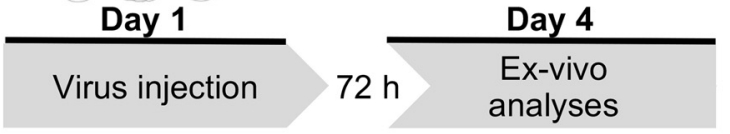

B
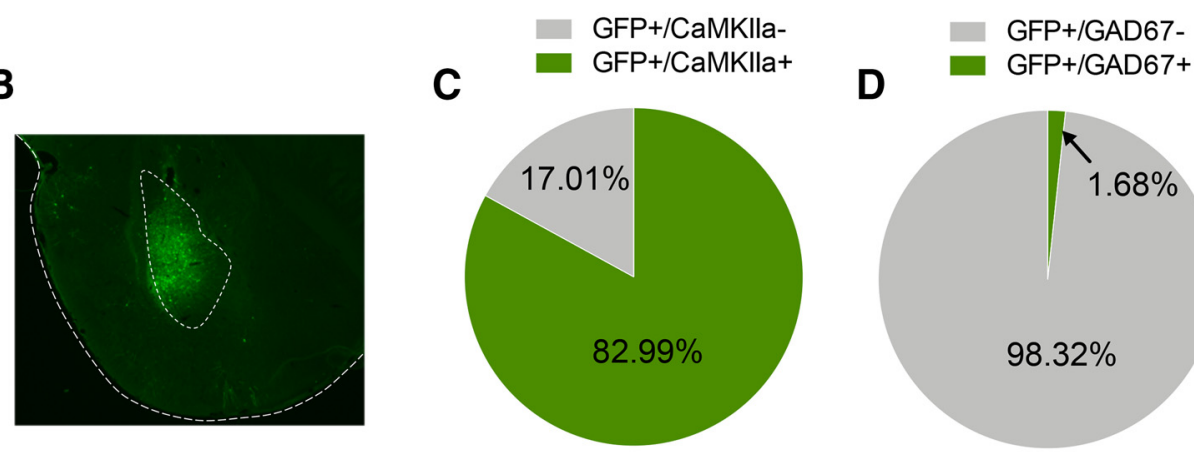

F
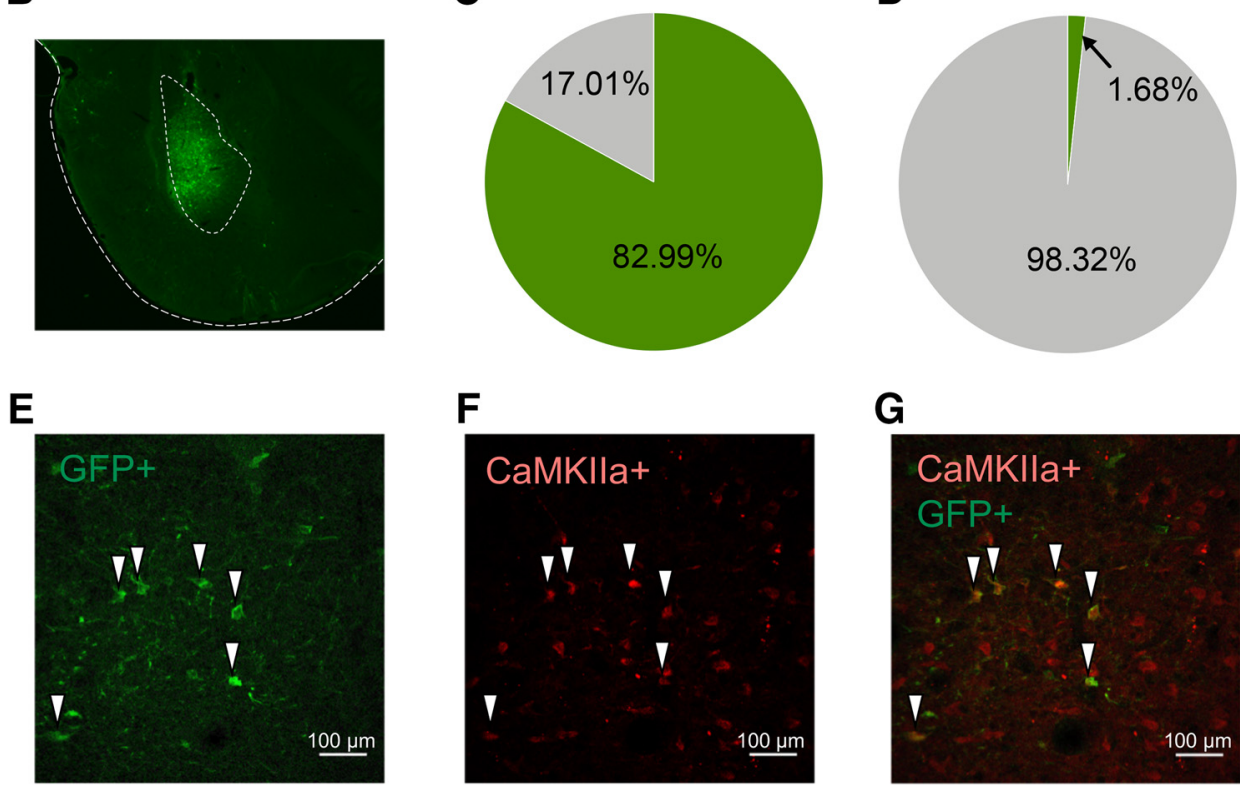

G
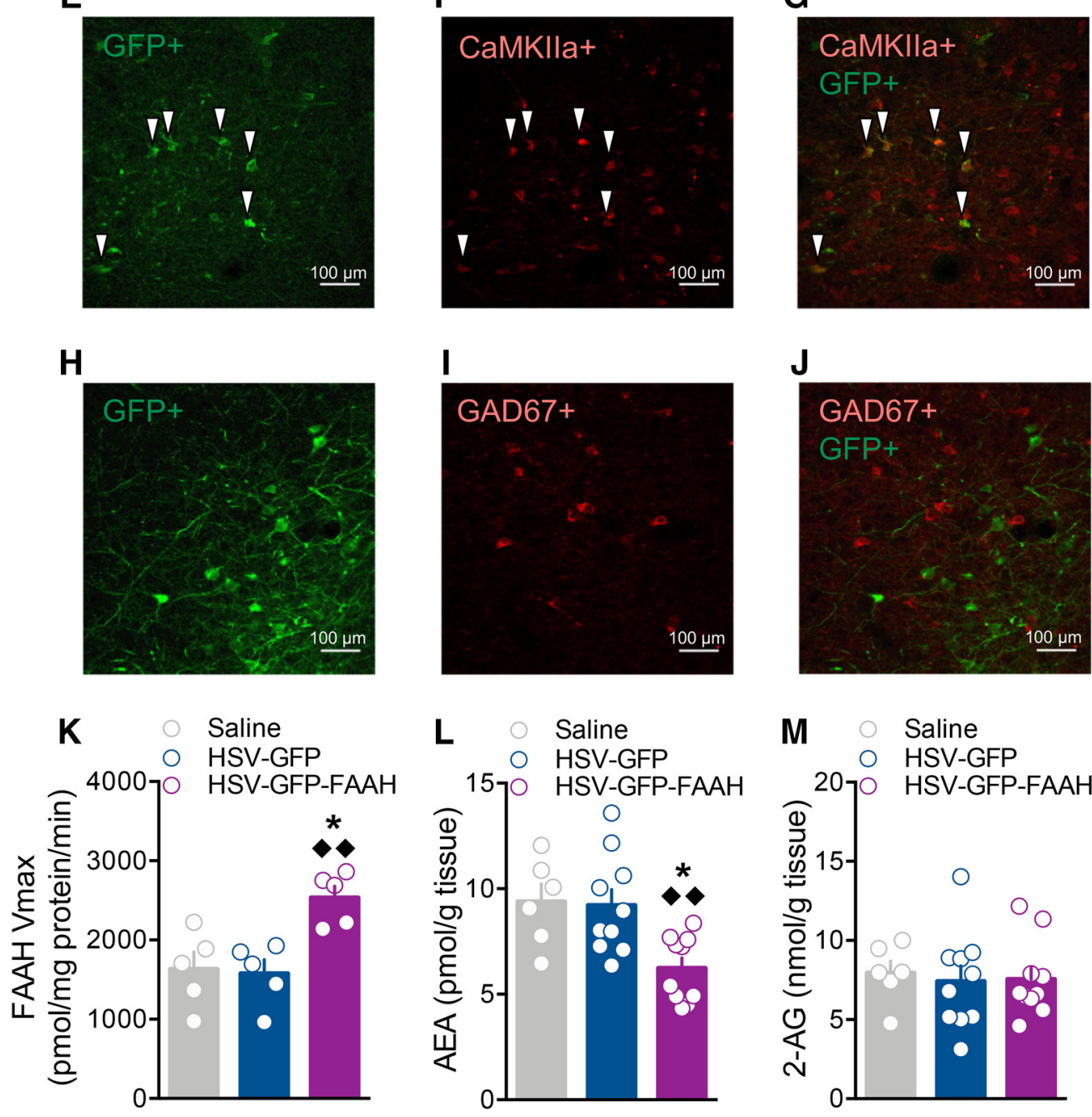

Figure 1. Anatomical localization and functional characterization of FAAH overexpression in the BLA. $A$, Schematic representation of the experimental design. Rats received bilateral intra-BLA injections of the HSV viral vector carrying GFP only, GFP-FAAH, or saline on day 1 and, $72 \mathrm{~h}$ later, on day 4, they were killed for double-immunofluorescence experiments, measurement of FAAH enzymatic activity, and determination of AEA and 2-AG levels in the BLA. B, Representative image of intra-BLA HSV injection ( $2 \times$ magnification). C, D, Quantification (Figure legend continues.) 
A HSV-GFP
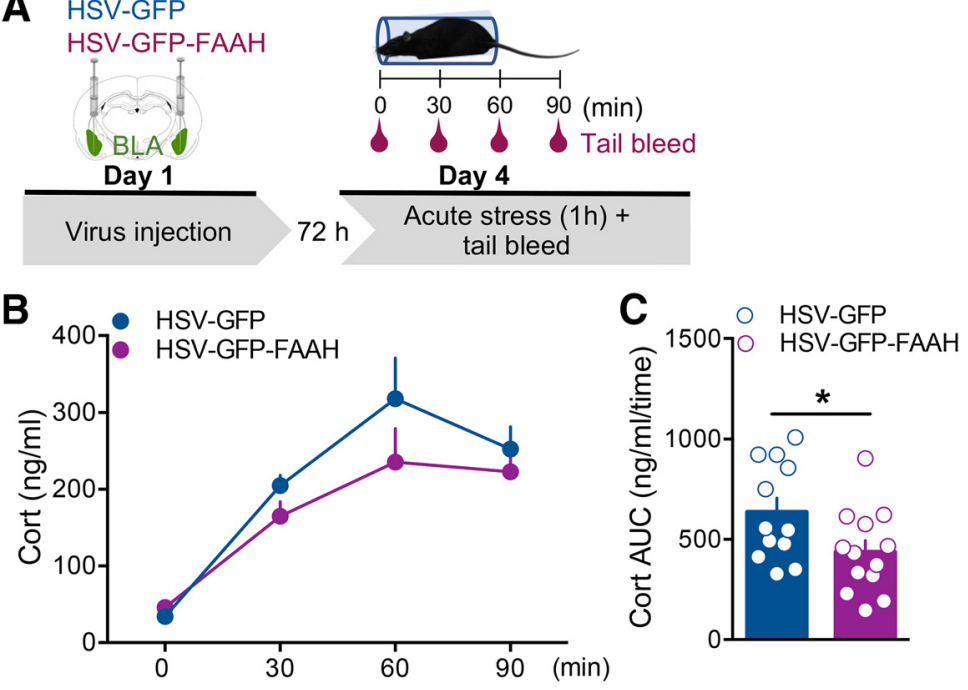

Figure 2. Intra-BLA FAAH overexpression decreased plasma corticosterone acute stress response. $\boldsymbol{A}$, Schematic representation of the experimental design. Rats received bilateral intra-BLA injections of the HSV viral vector carrying GFP only or GFP-FAAH on day 1 and, $72 \mathrm{~h}$ later, on day 4, underwent a $1 \mathrm{~h}$ restraint stress. Plasma corticosterone levels were measured at time $0,30,60$, and 90 min from stress onset. $\boldsymbol{B}$, Ninety-minute time course of plasma corticosterone levels (Cort, $\mathrm{ng} / \mathrm{ml}$ ). $\boldsymbol{C}$, Total plasma corticosterone stress response (area under the curve, AUC, $\mathrm{ng} / \mathrm{ml} /$ time). Rats injected with HSV-GFP-FAAH presented decreased total corticosterone stress response during the 90 -min time course compared with their HSV-GFP control group. Data are expressed as mean \pm SEM ( $n=12-13$ per group). ${ }^{*} p<0.05$.

total hormone (area under the curve) responses were calculated for both HSV-GFP and HSV-GFP-FAAH groups (Fig. 2C). Student's $t$ test revealed that the FAAH overexpression significantly decreased the total corticosterone stress response $\left(t_{(23)}=2.21\right.$, $p=0.04$ ) compared with the HSV-GFP control group (Fig. 2C).

In a separate cohort of animals, we examined the effects of intra-BLA FAAH overexpression on anxiety-like behavior. Fortyeight hours following virus microinjections, rats were tested in an EPM for $5 \mathrm{~min}$, then the following day in an LD box, and, immediately afterward, in an OF task for 10 min each (Fig. 3A). Very consistently, we found that the HSV-GFP-FAAH group showed less anxiety-like behavior across the behavioral tasks performed compared with the HSV-GFP control group. Specifically, in the EPM (Fig. 3B-E), we did not find a significant difference between groups in the percentage of time spent in open arms $\left(t_{(19)}=1.27\right.$, $p=0.22$; Fig. $3 B$ ); however, HSV-GFP-FAAH-injected rats showed a significant increase in the percentage of open arm en-

\footnotetext{
$\leftarrow$

(Figure legend continued.) $\quad$ of coexpressed $\mathrm{GFP}^{+}$and CaMKIla ${ }^{+}(\mathrm{C})$ and GFP ${ }^{+}$and GAD67 ${ }^{+}$ (D). Detailed quantification of cell phenotype infected by HSV-GFP in 11-12 rats shows that, following microinjection into the BLA, HSV predominately infected CaMKIlla ${ }^{+}$excitatory pyramidal neurons (82.99\%) and only very rare HSV-infected cells coexpressed GAD67 ${ }^{+}$, a marker of inhibitory neurons (1.68\%). $\boldsymbol{E}-\boldsymbol{G}$, Representative images of double-immunofluorescence staining in the BLA for GFP ${ }^{+}$(HSV-infected cells, green) (E), CaMKIla ${ }^{+}$(excitatory pyramidal neurons, red) $(\boldsymbol{F})$, and with merged channels (yellow) $(\boldsymbol{G})$. White arrowheads indicate GFP ${ }^{+}$ and CaMKIla ${ }^{+}$coexpression. $\boldsymbol{H}-\boldsymbol{J}$, Representative images of double-immunofluorescence staining in the BLA for GFP ${ }^{+}$(HSV-infected cells, green) $(\boldsymbol{H}), \mathrm{GAD} 67^{+}$(inhibitory neurons, red) $(\boldsymbol{I})$, and with merged channels (J). $\boldsymbol{K}$, FAAH maximal hydrolytic activity $\left(V_{\text {maxi }}\right.$ pmol/mg protein/ $\mathrm{min}$ ) in the amygdala. Rats injected with HSV-GFP-FAAH presented increased FAAH activity compared with rats injected with the control HSV-GFP vector or with saline only $(n=5$ per group). L, AEA levels (pmol/g tissue) in the amygdala. Rats injected with HSV-GFP-FAAH presented decreased AEA levels compared with rats injected with the control HSV-GFP vector or with saline only ( $n=6-10$ per group). $M, 2-A G$ levels ( $\mathrm{nmol} / \mathrm{g}$ tissue) in the amygdala. There were no differences in 2-AG levels among the three experimental groups $(n=6-10$ per group). Data are expressed as mean \pm SEM. ${ }^{*} p<0.05$ versus the corresponding saline group; $\checkmark p<0.01$ versus the corresponding HSV-GFP group.
}

tries $\left(t_{(19)}=2.19, p=0.04\right.$; Fig. $\left.3 C\right)$, and a significant decrease in the latency to first enter the open arms $\left(t_{(19)}=2.82, p=\right.$ 0.01 ; Fig. $3 D$ ) compared with HSV-GFPinjected rats. Animals in the HSV-GFPFAAH group also presented increased number of HDIPS $\left(t_{(19)}=2.94, p=0.008\right.$; Fig. $3 E$ ) compared with the HSV-GFP group. Moreover, there was no statistically significant difference between groups in the number of SAP $\left(t_{(19)}=0.69\right.$, $p=0.50$; HSV-GFP group: $9.75 \pm 1.63$; HSV-GFP-FAAH group: $11.33 \pm 1.52$ ). As a measure of exploratory behavior, number of HDIPS relates more to reduced anxiety-like behavior, whereas the number of SAP indicates a measure of risk assessment and tends to associate positively with anxious behavior (Rodgers et al., 1997, 1999; Bortolato et al., 2006; Morena et al., 2016a). These effects were not due to changes in motor activity because the different treatments did not affect the total number of entries in the closed arms during the 5 min test $\left(t_{(19)}\right.$ $=0.63, p=0.54$; HSV-GFP group: $5.17 \pm 0.83$; HSV-GFP-FAAH group: $6.00 \pm 1.07)$.

When animals were tested in the LD box, we found that HSVGFP-FAAH-injected rats presented increased percentage of time spent in the light section and light section entries $\left(t_{(20)}=2.68\right.$, $p=0.01 ; t_{(20)}=2.84, p=0.01 ;$ Fig. $3 F, G$, respectively) compared with control animals. Consistently, the HSV-GFP-FAAH group also presented a significant decrease in the latency to first enter the light section $\left(t_{(20)}=2.75, p=0.01\right.$; Fig. $\left.3 H\right)$. There was no significant difference in the attempts made to enter the light compartment between groups $\left(t_{(20)}=1.96, p=0.06\right.$; Fig. $\left.3 I\right)$. In the OF task, we did not find a difference between groups in the percentage of time spent in the center quadrant of the OF $\left(t_{(21)}=\right.$ $0.13, p=0.90$; Fig. $3 J)$, in the number of entries into the center section $\left(t_{(21)}=1.45, p=0.16\right.$; Fig. $\left.3 \mathrm{~K}\right)$, or in other behavioral indices of anxiety-like behavior (expressed as the sum of SAP and self-grooming events; $t_{(21)}=1.40, p=0.18$; Fig. $3 L$ ). No differences between groups were found in the total exploratory behavior (expressed as the sum of rearing and wall rearing events; $t_{(21)}=0.40, p=0.69$; HSV-GFP: $50.09 \pm 7.08$; HSV-GFP-FAAH: $46.67 \pm 4.98)$ or in the total distance traveled $\left(t_{(21)}=0.51, p=\right.$ 0.62 ; Fig. $3 M)$, thus further confirming that the treatment did not affect locomotor activity. Together, these results consistently indicate that intra-BLA FAAH overexpression induced an overall decrease in anxiety-like behavior.

\section{Intra-BLA FAAH overexpression selectively decreases conditioned fear expression during the extinction training and the first extinction retrieval sessions}

To test the effects of intra-BLA FAAH overexpression on fear memory expression, rats were trained in an auditory fear conditioning and, to not interfere with memory consolidation, they underwent surgical intra-BLA microinjection of HSV-GFP or HSV-GFP-FAAH 24 h later. Three days later, when the viral expression reached its peak, rats received extinction training followed by 3 consecutive days of extinction retrieval sessions (Fig. 4A) 

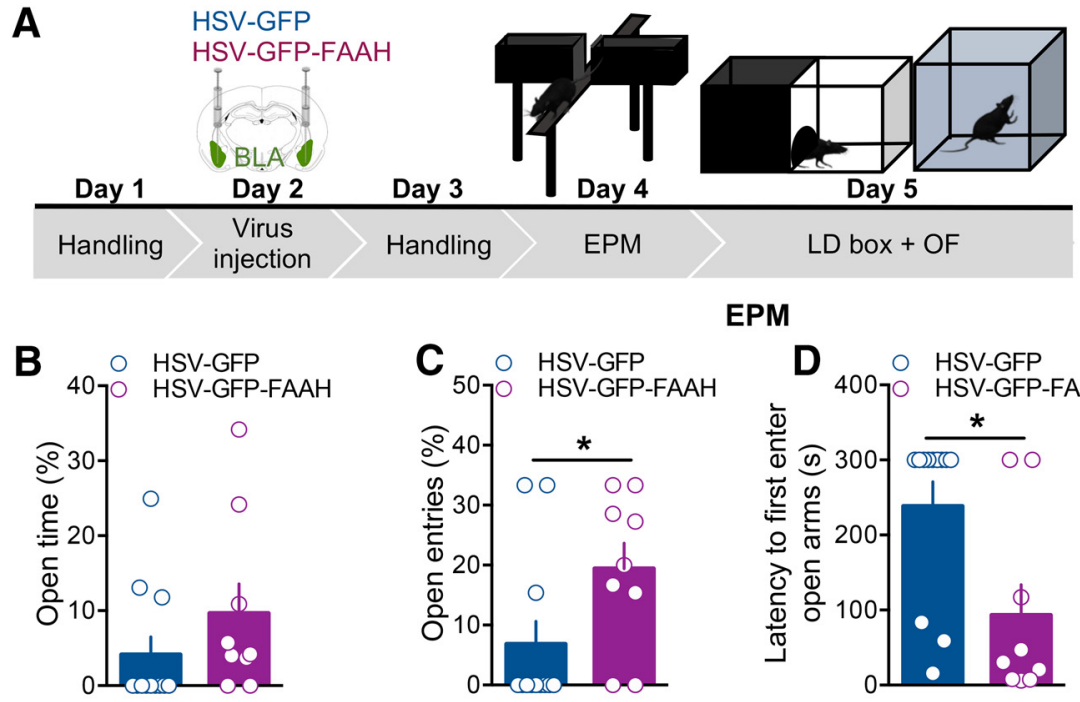

EPM
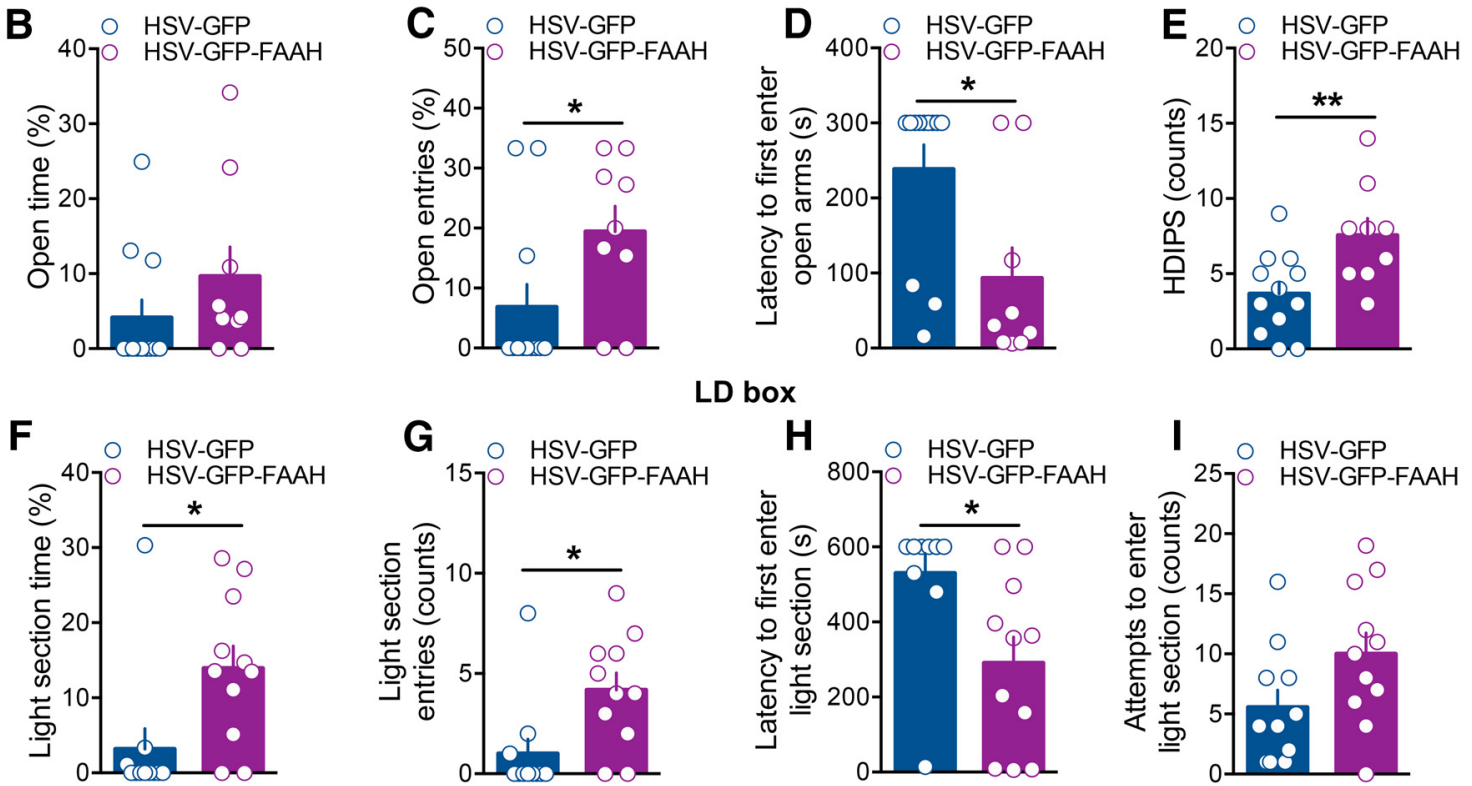

LD box
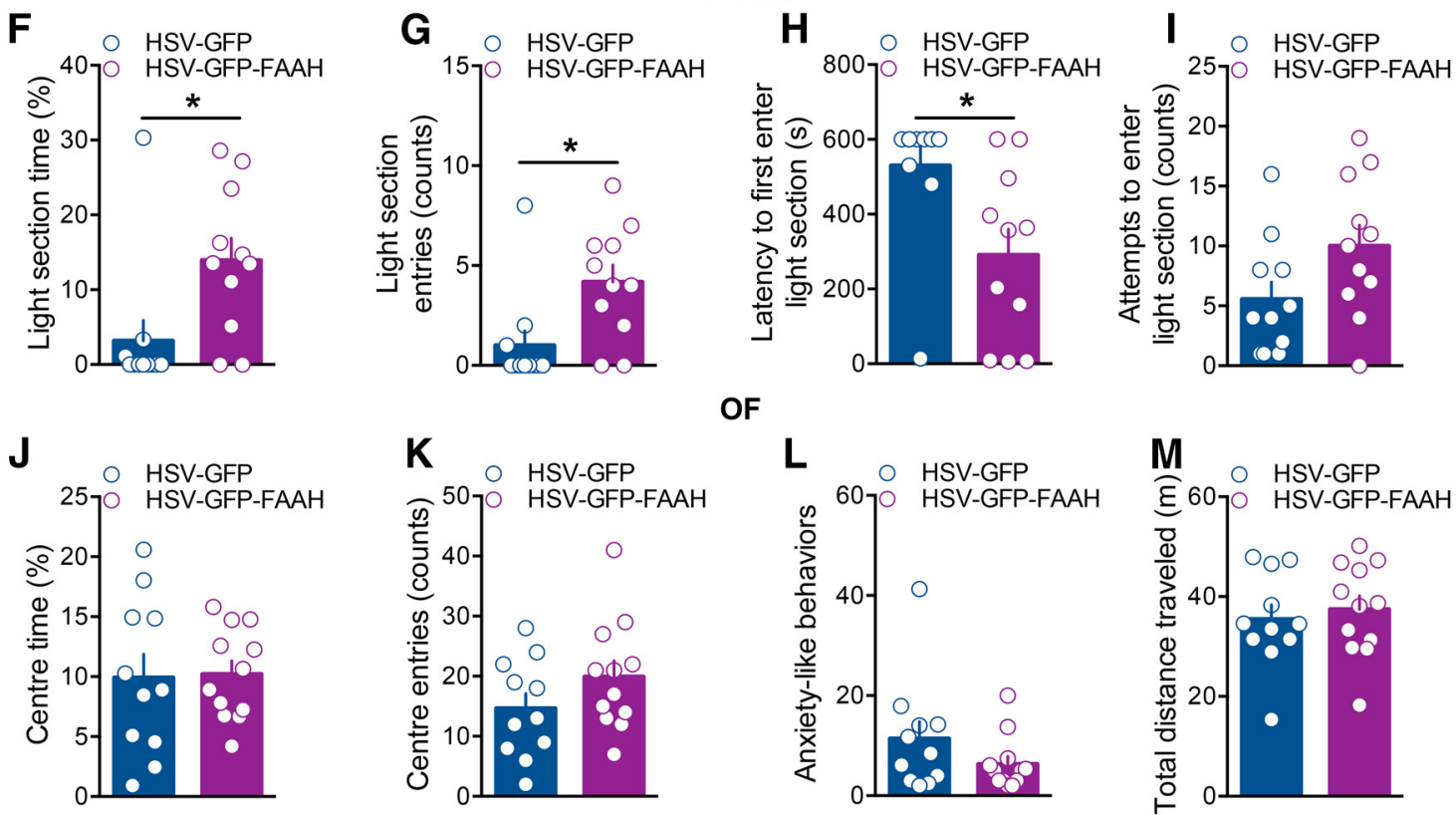

OF
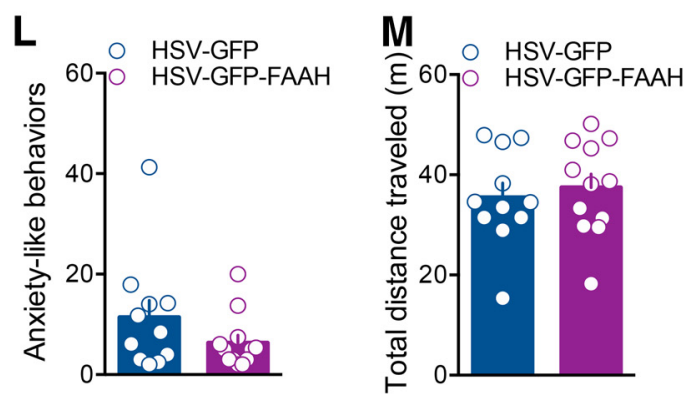

Figure 3. Intra-BLAFAAH overexpression decreased indices of anxiety-like behavior. A, Schematic representation of the experimental design. Rats were handled on day 1 and 3 , received bilateral intra-BLA injections of the HSV viral vector carrying GFP only or GFP-FAAH on day 2 and, $48 \mathrm{~h}$ later, on day 4 , underwent a 5 min-elevated plus maze test (EPM). On day 5 , rats were tested in an LD box for $10 \mathrm{~min}$ and immediately after, in an $0 \mathrm{~F}$ task for $10 \mathrm{~min}$. $\boldsymbol{B}-\boldsymbol{E}$, Intra-BLA FAAH overexpression decreased indices of anxiety-like behavior in the EPM. Effects of intra-BLA FAAH overexpression on percentage time spent in the open arms $(\boldsymbol{B})$, percentage of open arm entries $(\boldsymbol{C}$ ), latency to first enter the open arms (seconds) (D), HDIPS (counts) (E) in the EPM. $\boldsymbol{F}-\boldsymbol{I}$, Intra-BLA FAAH overexpression decreased indices of anxiety-like behavior in the LD box. Effects of intra-BLA FAAH overexpression on percentage time spent in the light section $(\boldsymbol{F})$, number of entries into the light section (counts) (G), latency to first enter the light section (seconds) $(\boldsymbol{H})$, and number of attempts to enter the light section (counts) (I), in the LD box. J-M, Intra-BLA FAAH overexpression did not alter locomotor activity in the $0 \mathrm{~F}$ task. Effects of intra-BLA FAAH overexpression on percentage time spent in the center section $(\boldsymbol{J})$, number of entries into the center section (counts) ( $K$ ), anxiety-like behaviors (sum of self-grooming and stretch attend posture events) ( $\boldsymbol{L}$ ), total distance traveled (meters) $(\boldsymbol{M})$ in the OF task. Data are expressed as mean \pm SEM $\left(n=9-12\right.$ per group). ${ }^{*} p<0.05$; ${ }^{* *} p<0.01$.

Repeated-measures ANOVA for CS-US-evoked freezing during conditioning revealed a significant CS-US presentation effect $\left(F_{(2,68)}=44.73, p<0.0001\right)$, no treatment $\left(F_{(1,34)}=0.06, p=\right.$ $0.81)$, or CS-US presentation $\times$ treatment interaction effect $\left(F_{(2,68)}=2.44, p=0.09\right.$; Fig. $\left.4 B\right)$, indicating that all rats acquired similar CS-evoked fear responses before viral administration and demonstrating that no preexisting differences were present between these groups. Unpaired Student's $t$ test for the average percentage freezing during the $5 \mathrm{~min}$ habituation (pre-CS period) revealed no baseline freezing difference to context A between the treatment groups $\left(t_{(34)}=0.23, p=0.82\right.$; Fig. $\left.4 B\right)$. As shown in Figure 4C, repeated-measures ANOVA for CS-evoked freezing during extinction training revealed significant CS presentation $\left(F_{(3,102)}=11.97, p<0.0001\right)$, treatment $\left(F_{(1,34)}=\right.$ $15.95, p=0.0003)$, and CS presentation $\times$ treatment interaction $\left(F_{(3,102)}=2.95, p=0.04\right)$ effects. Post hoc comparisons showed that HSV-GFP-FAAH-injected animals presented decreased average freezing during the first $5 \mathrm{CS}$ presentations compared with the HSV-GFP group ( $p<0.0001$; Fig. $4 C)$, suggesting that intraBLA FAAH overexpression reduces learned fear expression and fear memory retrieval. Unpaired Student's $t$ test for the average percentage freezing during the pre-CS period revealed no base- 
A

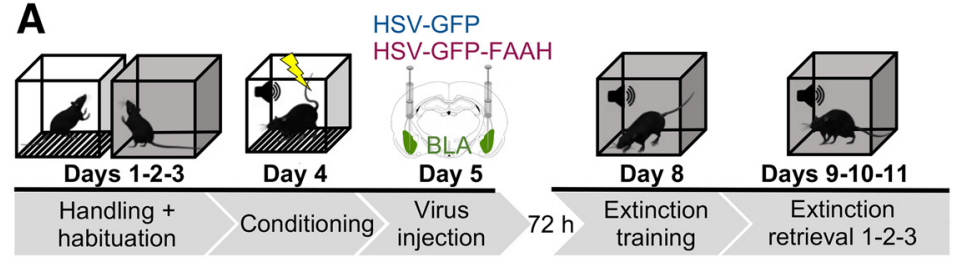

B

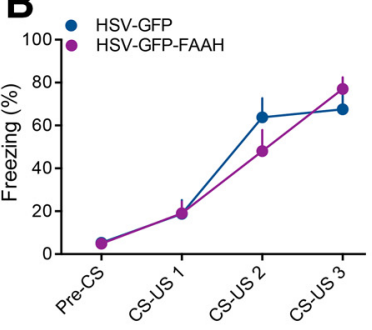

C

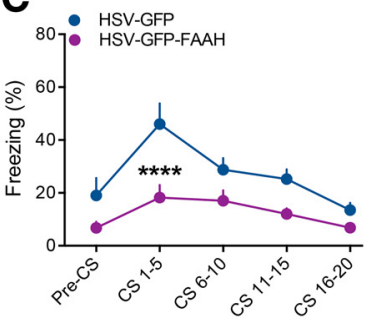

D
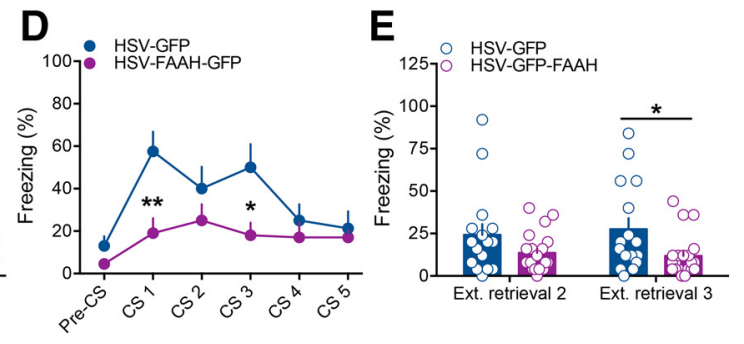

$\mathbf{F}$

HSV-GFP

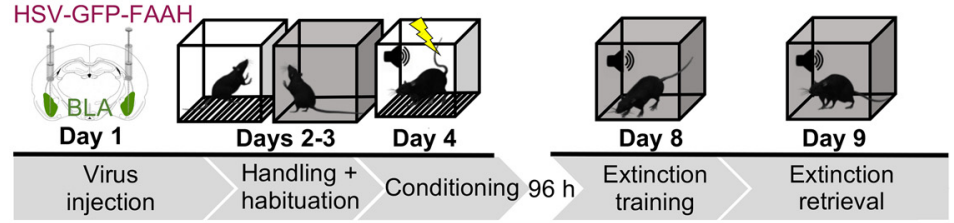

G

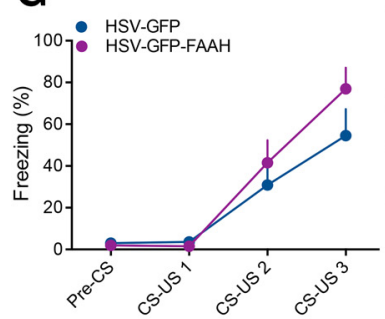

H

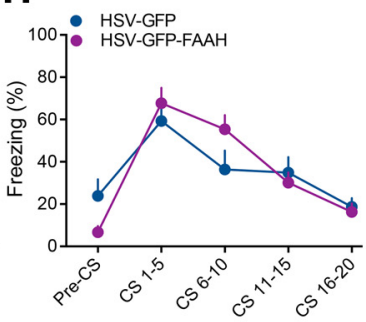

I
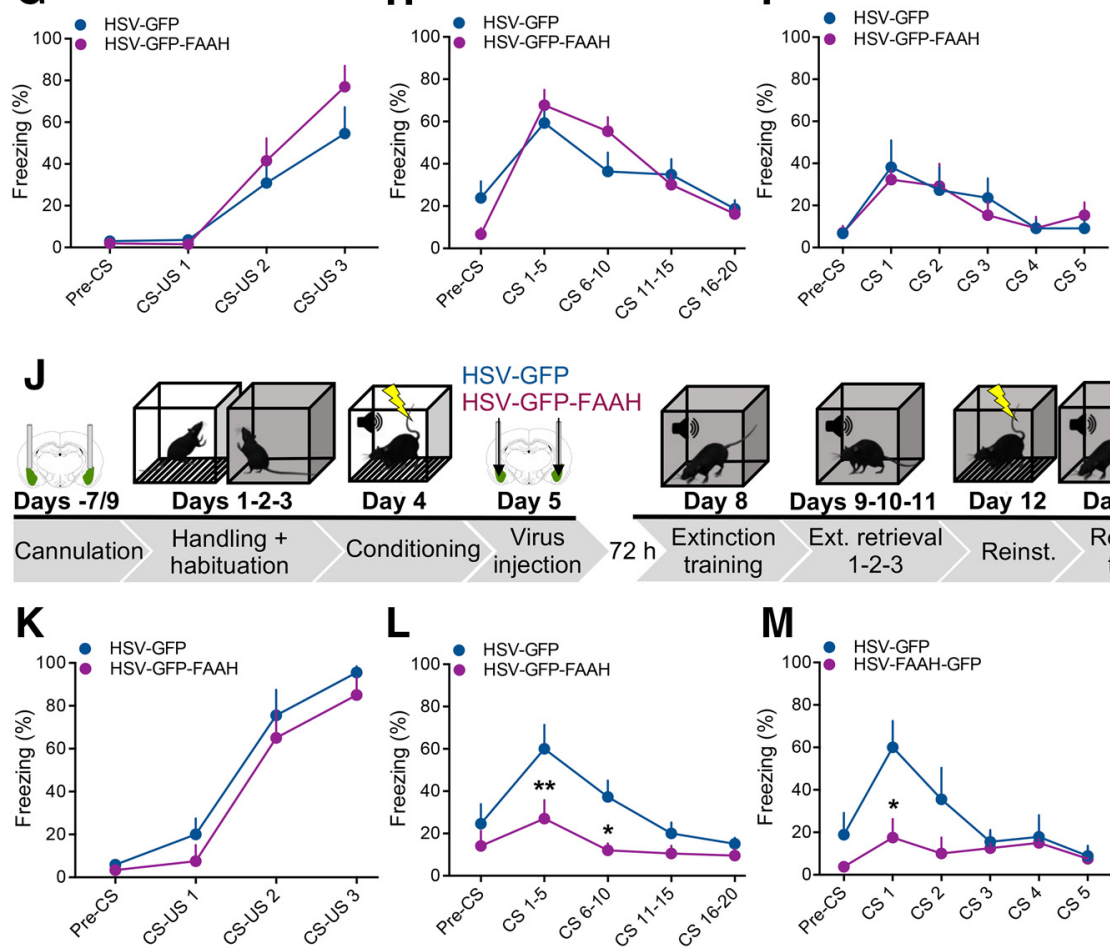

HSV-GFP

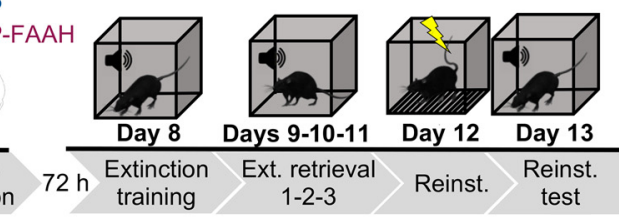

$\mathbf{L}$
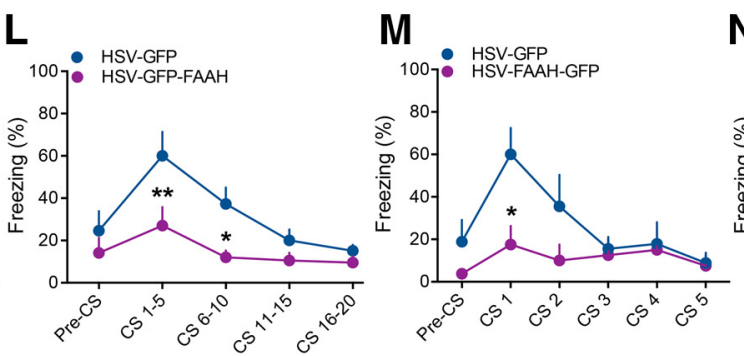

N

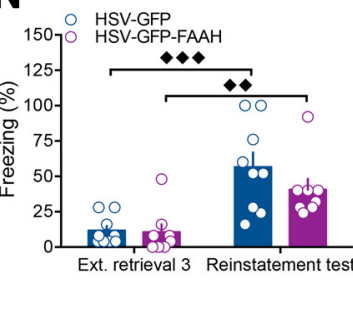

Figure 4. Intra-BLAFAAH overexpression selectively reduced conditioned fear expression. $A$, Schematic representation of the experimental design. Rats were handled on day 1 and, on days 2 and 3 , were handled and habituated to the experimental chambers. On day 4, animals were subjected to an auditory fear conditioning and, $24 \mathrm{~h}$ later (day 5), received bilateral intra-BLA surgical injections of HSV-GFP or HSV-GFP-FAAH. Seventy-two hours later, rats received a fear memory test/extinction training (day 8) and three consecutive extinction retrieval sessions (extinction retrieval 1,2 , and 3 ) on days $9-11 . \boldsymbol{B}-\boldsymbol{E}$, Intra-BLA FAAH overexpression at extinction training decreased conditioned fear expression/fear memory retrieval during the extinction training and extinction retrieval 1 and 3. $\boldsymbol{B}-\boldsymbol{E}$, Percentage freezing during cued fear conditioning $(\boldsymbol{B})$, extinction training $(\boldsymbol{C})$, extinction retrieval $1(\boldsymbol{D})$, and extinction retrieval 2 and $3(\boldsymbol{E})(n=16-20$ per group). $\boldsymbol{F}$, Schematic representation of the experimental design. Rats received bilateral intra-BLA surgical injections of HSV-GFP or HSV-GFP-FAAH on day 1 and, on days 2 and 3, they were handled and habituated to the experimental chambers. On day 4, animals were subjected to an auditory fear conditioning and $96 \mathrm{~h} \mathrm{later} \mathrm{received} \mathrm{a} \mathrm{fear} \mathrm{memory} \mathrm{test/extinction} \mathrm{training} \mathrm{(day} \mathrm{8)} \mathrm{and} \mathrm{an} \mathrm{extinction}$ retrieval session (day 9). G-I, Intra-BLA FAAH overexpression at fear conditioning did not affect the acquisition or the expression of cued fear conditioning and did not alter the animals' ability to express freezing behavior. $\mathbf{G}-\boldsymbol{I}$, Percentage freezing during cued fear conditioning $(\boldsymbol{G})$, extinction training $(\boldsymbol{H})$, and extinction retrieval $(\boldsymbol{I})(n=11-13$ per group). $\boldsymbol{J}$, Schematic representation of the experimental design. Rats received bilateral cannulation surgery aiming at the BLA 7-9 d before the behavioral experiment. Rats were handled on day 1 and, on days 2 and 3 , they were handled and habituated to the experimental chambers. On day 4, animals were subjected to an auditory fear conditioning and, $24 \mathrm{~h}$ later (day 5), received bilateral intra-BLA injections of HSV-GFP or HSV-GFP-FAAH through their cannulae. Seventy-two hours later, rats received a fear memory test/extinction training (day 8) and three consecutive extinction retrieval sessions (extinction retrieval 1,2 , and 3 ) on days $9-11$. On day 12 , rats were given unsignaled foot shocks and the following day tested for fear reinstatement (day 13). $\boldsymbol{K}-\boldsymbol{N}$, The cannulation surgery (Figure legend continues.) 
line freezing difference to context B between the HSV-GFP and HSV-GFP-FAAH groups $\left(t_{(34)}=1.91, p=0.07\right.$; Fig. $\left.4 C\right)$, thus indicating that FAAH overexpression did not affect unconditioned fear response. Repeated-measures ANOVA for freezing during extinction retrieval 1 revealed a significant effect of CS presentation $\left(F_{(4,136)}=4.02, p<0.004\right.$; Fig. $\left.4 D\right)$, treatment $\left(F_{(1,34)}=5.56, p<0.03\right.$; Fig. $\left.4 D\right)$, and CS presentation $\times$ treatment interaction $\left(F_{(4,136)}=3.19, p<0.02\right.$; Fig. $\left.4 D\right)$. Post hoc tests revealed that the HSV-GFP-FAAH group expressed lower freezing levels at the first and third CS presentations relative to the HSV-GFP control group ( $p<0.01$ and $p<0.05$, respectively; Fig. $4 D$ ), indicating that FAAH overexpression decreased fear memory expression. As shown in Figure 4E, there were no differences in the average freezing during the 5 CS presentations between groups at extinction retrieval $2\left(t_{(34)}=1.70, p=0.10\right.$; Fig. $4 E)$. However, the following day during the extinction retrieval 3 session, again, rats in the HSV-GFP-FAAH group showed significantly less freezing than the HSV-GFP group $\left(t_{(34)}=2.39, p=\right.$ 0.02 ; Fig. $4 E$ ). These results suggest that, overall, FAAH overexpression within the BLA reduced the expression or retrieval of learned fear.

To exclude the possibility that the impairing effects on memory retrieval and the reduction of fear expression were due to nonspecific effects of the virus infection on the rats' ability to express freezing behavior and to correctly acquire the CS-US association, we performed two additional experiments. In the first experiment, rats were surgically microinjected with the viral vectors on day 1 and fear conditioned $72 \mathrm{~h}$ later (day 4 ). On days 8 and 9 , animals underwent the extinction training and retrieval sessions to match the experimental design used in the previous experiments (Fig. 4F). As shown in Figure 4G, repeatedmeasures ANOVA for percentage of freezing during conditioning showed a significant CS-US presentation effect, but no treatment or CS-US presentation $\times$ treatment interaction effects $\left(F_{(2,44)}=24.73, p<0.0001 ; F_{(1,22)}=1.49, p=0.24 ; F_{(2,44)}=0.93\right.$, $p=0.40$; respectively; Fig. $4 G$ ), indicating that the HSV-GFPFAAH vector did not induce a general impairment in fear expression or in the acquisition of the aversive CS-US association because rats' freezing levels increased over time with the stimuli presentations. Student's $t$ test also revealed no group differences in baseline freezing levels to the conditioning context $\left(t_{(22)}=\right.$ $1.04, p=0.31$; Fig. $4 G$, freezing during pre-CS). Repeatedmeasures ANOVA for percentage of freezing during extinction training revealed a significant CS presentation, but no treatment or CS presentation $\times$ treatment interaction effects $\left(F_{(3,66)}=\right.$ $32.54, p<0.0001 ; F_{(1,22)}=0.50, p=0.49 ; F_{(3,66)}=2.54, p=0.06$; respectively; Fig. $4 H$ ), indicating that both groups were equally able to retrieve the aversive experience and to show within session extinction. Unpaired Student's $t$ test for the average percentage freezing during the pre-CS period revealed no baseline freezing difference to context B between the HSV-GFP and HSV-GFP-

(Figure legend continued.) itself did not affect the effect of the FAAH overexpression at extinction training to reduce conditioned fear expression/fear memory retrieval during the extinction training and extinction retrieval 1. Additionally, intra-BLA FAAH overexpression did not affect fear reinstatement, thus demonstrating no treatment effects on the ability to show freezing behavior and that all experimental groups had correctly acquired the original tone-shock memory association. $\boldsymbol{K}-\boldsymbol{N}$, Percentage freezing during cued fear conditioning $(\boldsymbol{K})$, extinction training $(\boldsymbol{L})$, extinction retrieval $1(\boldsymbol{M})$, and extinction retrieval 3 and fear reinstatement test $(\boldsymbol{M})$ ( $n=8-9$ per group). Data are expressed as mean \pm SEM. ${ }^{*} p<0.05,{ }^{* *} p<0.01,{ }^{* * * *} p<$ 0.0001 versus the corresponding HSV-GFP group. $\diamond p<0.01, \diamond \diamond p<0.001$ versus the corresponding extinction retrieval 3 group.
FAAH groups $\left(t_{(22)}=1.76, p=0.09\right.$; Fig. $\left.4 H\right)$, thus indicating that FAAH overexpression did not affect unconditioned fear response. Repeated-measures ANOVA for freezing during extinction retrieval revealed a significant CS presentation effect $\left(F_{(4,88)}=\right.$ $5.44, p=0.0006$; Fig. $4 I$ ), but no significant effects of treatment or interaction between both factors $\left(F_{(1,22)}=0.02, p=0.89 ; F_{(4,88)}=\right.$ $0.40, p=0.81$, respectively; Fig. $4 I)$, indicating that administration of the HSV-GFP-FAAH vector before fear conditioning did not alter subsequent fear memory extinction retrieval.

In the second experiment, rats were tested in auditory fear conditioning as indicated above and after the extinction had occurred in both groups, rats were given unsignaled foot shocks in a different context and tested for fear reinstatement (Fig. 4J). Additionally, these rats were surgically implanted with cannulae aiming at the BLA 7-9 $\mathrm{d}$ before behavioral testing and the virus injections were delivered through the cannulae (Fig. $4 J$ ). These rats were implanted with cannulae to also determine whether the cannulation surgery itself affected the primary effect of the FAAH overexpression to reduce fear retrieval before pursuing the pharmacological intervention studies shown in the following paragraphs.

As shown in Figure $4 K$, repeated-measures ANOVA for percentage of freezing during conditioning showed a significant CS-US presentation effect, but no treatment or CS-US presentation $\times$ treatment interaction effects $\left(F_{(2,30)}=56.19, p<0.0001\right.$; $F_{(1,15)}=1.41, p=0.25 ; F_{(2,30)}=0.01, p=0.99$; respectively; Fig. $4 K)$, indicating the absence of preexisting differences between groups before the virus injections and that all rats correctly acquired the task. Student's $t$ test also revealed no group differences in baseline freezing levels to the conditioning context $\left(t_{(15)}=\right.$ $1.00, p=0.33$; Fig. $4 K$, freezing during pre-CS). Repeatedmeasures ANOVA for percentage of freezing during extinction training revealed a significant CS presentation, treatment, and CS presentation $\times$ treatment interaction effects $\left(F_{(3,45)}=15.82, p<\right.$ $0.0001 ; F_{(1,15)}=6.69, p=0.02 ; F_{(3,45)}=3.36, p=0.03$; respectively; Fig. $4 L$ ). Consistent with our previous results obtained from animals without cannulation surgery (Fig. 4C), post hoc analyses showed that rats injected with HSV-GFP-FAAH virus presented significantly lower freezing levels during the first $10 \mathrm{CS}$ presentations on average (CS $1-5, p<0.01$; CS $6-10, p<0.05$; Fig. $4 L$ ). Unpaired Student's $t$ test for the average percentage freezing during the pre-CS period revealed no baseline freezing difference to context B between the HSV-GFP and HSV-GFPFAAH groups $\left(t_{(15)}=0.88, p=0.39\right.$; Fig. $\left.4 L\right)$, thus indicating that FAAH overexpression did not affect unconditioned fear response. Again, similar to what we found in the experiment without cannulation surgery (Fig. $4 D$ ), repeated-measures ANOVA for freezing during extinction retrieval 1 revealed a significant CS presentation effect $\left(F_{(4,60)}=5.20, p=0.001\right.$; Fig. $\left.4 M\right)$, a significant treatment effect $\left(F_{(1,15)}=2.45, p=0.14\right)$, and a significant interaction between both factors $\left(F_{(4,60)}=3.19, p=0.02\right.$; Fig. $4 M)$. Post hoc tests revealed that the HSV-GFP-FAAH group expressed lower freezing levels at the first CS presentation relative to the HSV-GFP control group ( $p<0.05$; Fig. $4 M)$, indicating that the FAAH overexpression decreased fear expression. Both groups of rats successfully extinguished the fear memory when tested for extinction retrieval 2 and 3 the following $2 \mathrm{~d}$, showing no significant differences between groups in their freezing levels during both extinction retrieval $2\left(t_{(15)}=0.36, p=0.73\right.$; HSV-GFP: $16.03 \pm 4.31$; HSV-GFP-FAAH: $13.00 \pm 7.59)$ and extinction retrieval $3\left(t_{(15)}=0.16 ; p=0.87\right.$; Fig. $\left.4 N\right)$. After the extinction had successfully occurred in both groups, rats were given unsignaled foot shocks in a different context (context $\mathrm{C}$ ) and tested for fear reinstatement in the extinction context (context B). 

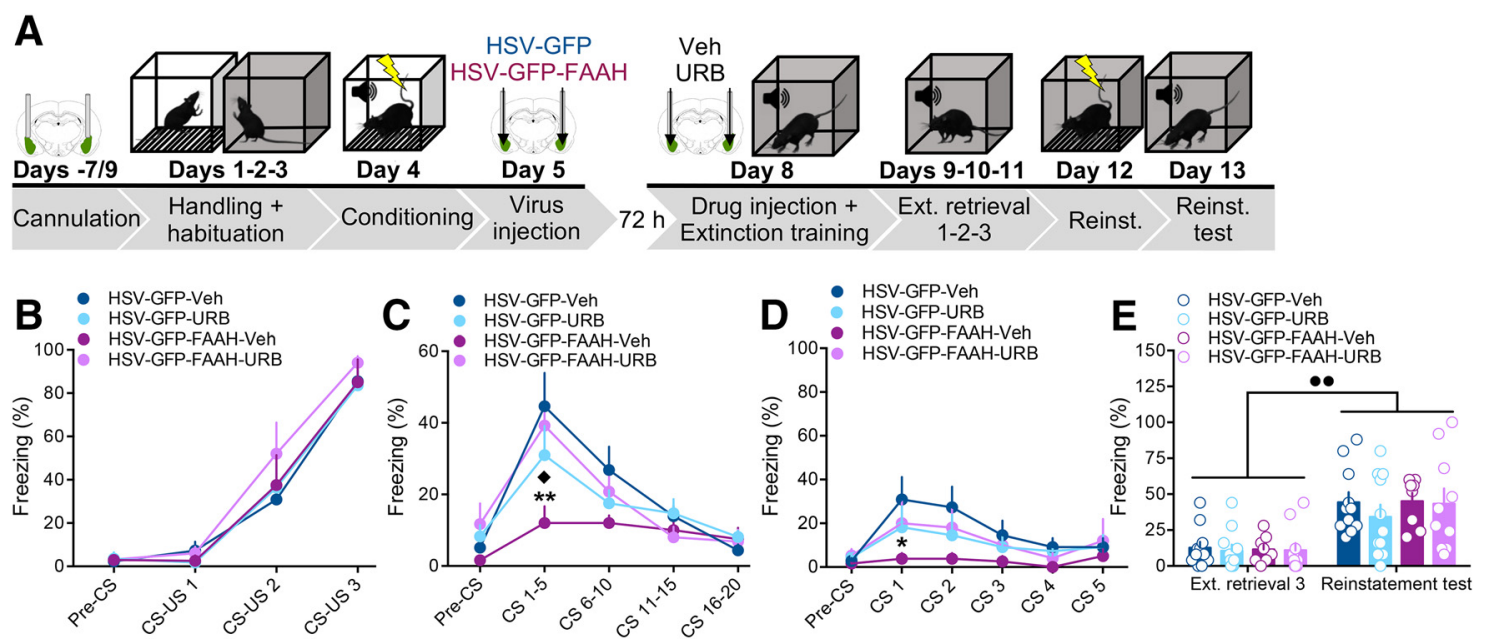

Figure 5. The FAAH inhibitor URB597 reverted the impairing effects of intra-BLA FAAH overexpression on conditioned fear expression. A, Schematic representation of the experimental design. Rats received bilateral cannulation surgery aiming at the BLA 7-9 d before the behavioral experiment. Rats were handled on day 1 and, on days 2 and 3 , they were handled and habituated to the experimental chambers. On day 4, animals were subjected to an auditory fear conditioning and, $24 \mathrm{~h}$ later (day 5), received bilateral intra-BLA injections of HSV-GFP or HSV-GFP-FAAH through their cannulae. On day 8, rats received intra-BLA injections of the FAAH inhibitor URB597 (URB, $10 \mathrm{ng} / \mathrm{side}$ ) or its vehicle (Veh) $1 \mathrm{~h}$ before the fear memory test/extinction training. They received three consecutive extinction retrieval sessions (extinction retrieval 1,2, and 3) on days 9-10-11. On day 12, rats were given unsignaled foot shocks and the following day tested for fear reinstatement (day 13). $\boldsymbol{B}-\boldsymbol{E}$, The FAAH inhibitor URB597 reverted the impairing effects of intra-BLA FAAH overexpression on conditioned fear expression at extinction training and extinction retrieval 1, but did not affect fear reinstatement. $\boldsymbol{B}-\boldsymbol{E}$, Percentage freezing during cued fear conditioning, extinction training $(\boldsymbol{C})$, extinction retrieval $1(\boldsymbol{D})$, and extinction retrieval 3 and fear reinstatement test $(\boldsymbol{E})$. Data are expressed as mean \pm SEM $\left(n=8-11\right.$ per group). ${ }^{*} p<0.05,{ }^{* *} p<0.01$ versus the corresponding HSV-GFP-Veh group. $p<0.05$ versus the corresponding HSV-GFP-FAAH-URB group. 00 - $p<01$ versus the corresponding extinction retrieval 3 groups.

Repeated-measures ANOVA for total freezing during CS presentations at extinction retrieval 3 and test for reinstatement revealed a significant time of test effect $\left(F_{(1,15)}=40.97, p<0.0001\right.$; Fig. $4 N$ ), but no effects of treatment or interaction between both factors $\left(F_{(1,15)}=0.98, p=0.34 ; F_{(1,15)}=1.62, p=0.22\right.$, respectively; Fig. $4 N)$. Both groups of rats showed increased freezing $24 \mathrm{~h}$ after the unsignaled foot shocks (reinstatement) relative to the last extinction retrieval session (extinction retrieval 3; $p<$ 0.001, $p<0.01$ for the HSV-GFP and the HSV-GFP-FAAH group, respectively; Fig. $4 N$ ).

Collectively, these data indicate that both groups had retained the original aversive CS-US association and that the effects of the FAAH overexpression specifically reduced learned fear response and fear memory retrieval during the extinction training and the first extinction retrieval session without altering the animals' ability to express freezing behavior. Furthermore, we found that even following BLA cannulation surgery, administration of the HSV-GFP-FAAH virus reduced learned fear expression relative to the HSV-GFP group, indicating that this effect was stable and replicable even with the introduction of a cannulation surgery.

\section{The FAAH inhibitor URB597 reverts the impairing effects of intra-BLA FAAH overexpression on learned fear expression during both extinction training and the first extinction retrieval session}

To test for the specificity of FAAH overexpression effects on fear memory dynamics, two groups of rats received cannulation surgery and 7-9 d later underwent an auditory fear conditioning paradigm, as described above. One day after conditioning, animals received either intra-BLA HSV-GFP or HSV-GFP-FAAH injections and were left in their colony room undisturbed to reach the maximal protein expression for $72 \mathrm{~h}$. Three days after HSV injection, the HSV-GFP and HSV-GFP-FAAH groups were further divided in two subgroups and given intra-BLA injections of the FAAH inhibitor URB597 (10 ng/side) or its vehicle $1 \mathrm{~h}$ before extinction training. They were subsequently tested for ex- tinction retrieval for 3 consecutive days and underwent a fear reinstatement protocol (Fig. 5A).

As shown in Figure $5 B$, repeated-measures ANOVA for percentage of freezing during CS-US presentations at conditioning revealed a significant CS-US presentation effect $\left(F_{(2,72)}=123.5\right.$, $p<0.0001$; Fig. $5 B$ ), but no treatment or CS-US presentation $\times$ treatment interaction effects $\left(F_{(3,36)}=0.85, p=0.47 ; F_{(6,72)}=\right.$ $0.40, p=0.87$, respectively; Fig. $5 B)$. There was no difference between the groups in pre-CS freezing during the fear conditioning session (HSV effect: $F_{(1,36)}=0.007, p=0.93$; drug effect: $F_{(1,36)}=0.15, p=0.70$; HVS $\times$ drug interaction effect: $F_{(1,36)}=$ $0.06, p=0.80$; Fig. $5 B$ ), thus showing that all groups correctly acquired the CS-US association and did not present unconditioned freezing to the context. Repeated-measures ANOVA for freezing during CS presentations at extinction training did not reveal a significant treatment effect $\left(F_{(3,36)}=1.69, p=0.19\right.$; Fig. $5 C)$, but did show significant CS presentation and CS presentation $\times$ treatment interaction effects $\left(F_{(3,108)}=23.39, p<0.0001\right.$; $F_{(9,108)}=2.34, p=0.02$, respectively; Fig. $5 C$ ). Confirming our previous results, post hoc analyses showed that the HSV-GFPFAAH group given vehicle injections (HSV-GFP-FAAH-Veh) presented significantly lower freezing levels during CS $1-5$ than the HSV-GFP-Veh group $(p<0.01$; Fig. $5 C)$. Furthermore, within the HSV-GFP-FAAH group, rats given vehicle showed significantly less freezing at CS 1-5 than rats given URB597 (HSV-GFP-FAAH-URB; $p<0.05$; Fig. $5 C$ ). There were no differences in freezing levels during CS presentations among the other treatment groups. Analyses of percentage freezing during the pre-CS period showed no significant effects of HSV, drug, or HSV $\times$ drug interaction $\left(F_{(1,36)}=0.000007, p=0.99 ; F_{(1,36)}=\right.$ 3.56, $p=0.07 ; F_{(1,36)}=0.97, p=0.33$, respectively; Fig. $\left.5 C\right)$. These results show that intra-BLA FAAH inhibition with URB597 completely counteracted the effects of FAAH overexpression on extinction training without affecting freezing behavior per se. Consistent with what we found in the previous experiments, repeatedmeasures ANOVA for freezing during extinction retrieval 1 revealed 

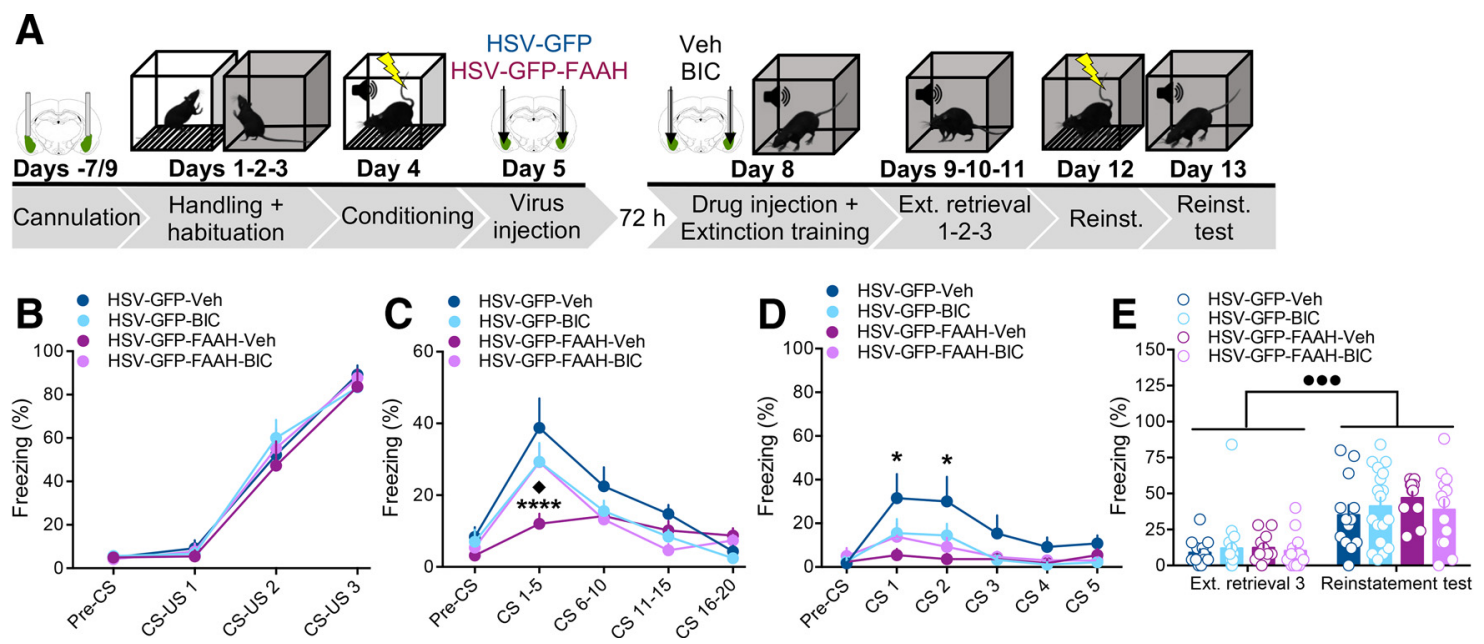

Figure 6. The GABA antagonist BIC blocked the impairing effects of intra-BLA FAAH overexpression on conditioned fear expression. $A$, Schematic representation of the experimental design. Rats received bilateral cannulation surgery aiming at the BLA 7-9 d before the behavioral experiment. Rats were handled on day 1 and, on days 2 and 3 , they were handled and habituated to the experimental chambers. On day 4, animals were subjected to an auditory fear conditioning and, $24 \mathrm{~h}$ later (day 5), received bilateral intra-BLA injections of HSV-GFP or HSV-GFP-FAAH through their cannulae. On day 8 , rats received intra-BLA injections of the $\mathrm{GABA}_{A}$ antagonist $\mathrm{BIC}(50 \mathrm{ng} / \mathrm{side})$ or its vehicle (Veh) $1 \mathrm{~h}$ before the fear memory test/extinction training. They received three consecutive extinction retrieval sessions (extinction retrieval 1,2 , and 3 ) on days $9-11$. On day 12 , rats were given unsignaled foot shocks and the following day tested for fear reinstatement (day 13 ). $\boldsymbol{B}-\boldsymbol{E}$, The $G A B A_{A}$ antagonist BIC blocked the impairing effects of intra-BLA FAAH overexpression on conditioned fear expression at extinction training, but did not affect fear reinstatement. $\boldsymbol{B}-\boldsymbol{E}$, Percentage freezing during cued fear conditioning $(\boldsymbol{B})$, extinction training $(\boldsymbol{C})$, extinction retrieval $1(\boldsymbol{D})$, and extinction retrieval 3 and fear reinstatement test $(\boldsymbol{E})$. Data are expressed as mean \pm SEM $(n=11-18$ per group). ${ }^{*} p<0.05,{ }^{* * *} p<0.0001$, HSV-GFP-Veh versus HSV-GFP-FAAH-Veh. $\diamond p<0.05$, HSV-GFP-FAAH-Veh vs HSV-GFP-FAAH-BIC. $\bigcirc 00<0.001$ versus the corresponding extinction retrieval 3 groups.

a significant CS presentation effect $\left(F_{(4,144)}=3.88, p=0.005\right.$; Fig. $5 D)$, but no significant effects of treatment or interaction between both factors $\left(F_{(3,36)}=1.35, p=0.27 ; F_{(12,144)}=0.56, p=0.87\right.$, respectively; Fig. 5D). Post hoc tests revealed that the HSV-GFPFAAH-Veh group expressed lower freezing levels at the first CS presentation relative to the HSV-GFP-Veh control group $(p<$ 0.05 ; Fig. $5 D$ ), indicating that the FAAH overexpression decreased learned fear expression. There were no significant differences between the HSV-GFP-Veh and the HSV-GFP-URB groups or between the HSV-GFP-Veh and the HSV-GFP-FAAHURB groups, indicating that URB597 given to rats with FAAH overexpressed in the BLA rendered their freezing levels comparable to those shown by control (HSV-GFP-Veh) animals.

All four experimental groups successfully extinguished the fear memory when tested for extinction retrieval 2 and 3. Specifically, two-way ANOVA for total freezing during the 5 CS presentations at extinction retrieval 2 revealed no significant HSV $\left(F_{(1,36)}=0.28, p=0.60\right)$, drug $\left(F_{(1,36)}=1.12, p=0.30\right)$, or $\mathrm{HSV} \times$ drug interaction effects $\left(F_{(1,36)}=2.51, p=0.12\right.$; percentage freezing for HSV-GFP-Veh: $14.55 \pm 6.20$, HSV-GFP-URB: $11.27 \pm 4.54$, HSV-GFP-FAAH-Veh: $8.00 \pm 2.39$, HSV-GFPFAAH-URB: $24.40 \pm 8.71)$. Similarly, two-way ANOVA for total freezing during the $5 \mathrm{CS}$ presentations at extinction retrieval 3 revealed no significant $\operatorname{HSV}\left(F_{(1,36)}=0.01, p=0.91\right)$, drug $\left(F_{(1,36)}=0.11, p=0.74\right)$, or HSV $\times$ drug interaction effects $\left(F_{(1,36)}=0.03, p=0.87\right.$; Fig. $\left.5 E\right)$.

After fear memory extinction had successfully occurred in all groups, rats were fear reinstated and tested for conditioned fear memory the day after. Repeated-measures ANOVA for total freezing during CS presentations at extinction retrieval 3 and test for reinstatement revealed a significant time of test effect $\left(F_{(1,36)}=\right.$ 93.92, $p<0.0001$; Fig. $5 E)$, but no effects of treatment or interaction between both factors $\left(F_{(3,36)}=0.25, p=0.86 ; F_{(3,36)}=\right.$ $0.55, p=0.65$, respectively; Fig. $5 E)$. All groups of rats showed increased freezing to the CS presentations $24 \mathrm{~h}$ after the reinstatement relative to their last extinction retrieval session $(p<0.01$, for the HSV-GFP-URB group; $p<0.0001$, for the remaining groups; Fig. $5 E$ ).

Collectively, the finding that the FAAH inhibitor URB597 completely abolished the effects of FAAH overexpression on conditioned fear expression and fear memory retrieval further confirms that the specificity of the effects seen with HSV-GFP-FAAH injection were explicitly due to overexpression of FAAH itself.

Intra-BLA GABA $\mathrm{A}_{\mathrm{A}}$ antagonism reverts the detrimental effects of FAAH overexpression on conditioned fear expression and fear memory retrieval

The behavioral effects produced by FAAH overexpression were relatively similar to what would be found by either blocking glutamatergic neurotransmission or increasing GABAergic neurotransmission. Because AEA signaling at $\mathrm{CB} 1 \mathrm{R}$ in the BLA reduces the release of GABA and glutamate (Azad et al., 2004; Shin et al., 2010; Gunduz-Cinar et al., 2016), a loss of AEA signaling would be expected to result in increased release of both or either of these neurotransmitters. However, an increase in glutamatergic transmission would be expected to enhance behavioral indices of fear (Lee et al., 2001), whereas an increase in GABA release due to a loss of inhibitory AEA signaling at GABAergic synapses would be consistent with the behavioral effects found (Rea et al., 2011). Therefore, to examine the possible involvement of GABAergic transmission in the effects of FAAH overexpression on conditioned fear memory retrieval and extinction, a separate cohort of animals was tested in the same behavioral paradigm as the one used for the previous experiment except that half of the rats were given intra-BLA injections of the $\mathrm{GABA}_{\mathrm{A}}$ antagonist $\mathrm{BIC}(50 \mathrm{ng} /$ side) $1 \mathrm{~h}$ before the extinction training session (Fig. 6A).

As shown in Figure $6 B$, repeated-measures ANOVA for percentage of freezing during CS-US presentations at conditioning revealed a significant CS-US presentation effect $\left(F_{(2,102)}=149.1\right.$, $p<0.0001$; Fig. $6 B$ ), but no treatment or CS-US presentation $\times$ treatment interaction effects $\left(F_{(3,51)}=0.27, p=0.85 ; F_{(6,102)}=\right.$ 


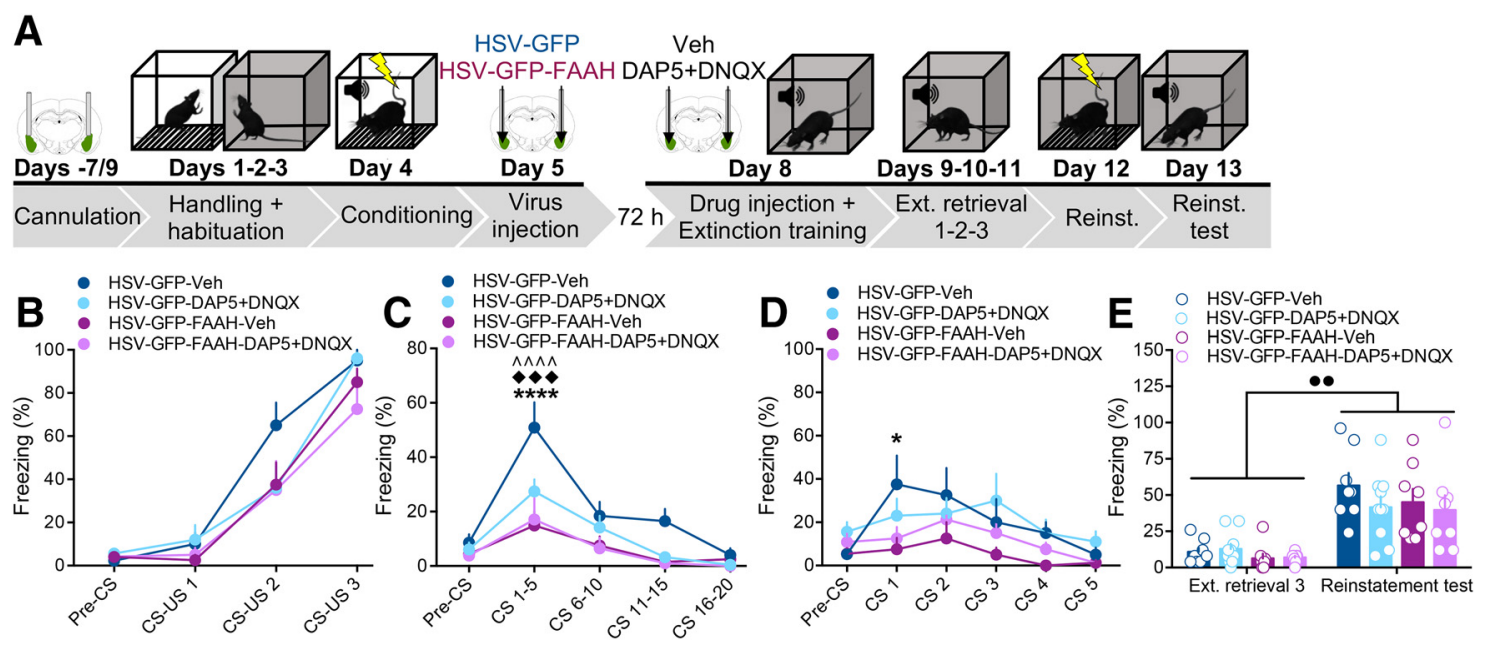

Figure 7. The NMDA receptor antagonist D-AP5 together with the AMPA/kainate receptor antagonist DNQX did not affect the impairing effects of intra-BLA FAAH overexpression on conditioned fear expression. A, Schematic representation of the experimental design. Rats received bilateral cannulation surgery aiming at the BLA 7-9 d before the behavioral experiment. Rats were handled on day 1 and, on days 2 and 3, they were handled and habituated to the experimental chambers. On day 4, animals were subjected to an auditory fear conditioning and, $24 \mathrm{~h} \mathrm{later} \mathrm{(day} 5$ ), received bilateral intra-BLA injections of HSV-GFP or HSV-GFP-FAAH through their cannulae. On day 8, rats received intra-BLA injections of the NMDA + AMPA/kainate receptor antagonists D-AP5 + DNQX (DAP5 + DNQX, $5 \mu \mathrm{g}+1 \mu \mathrm{g} / \mathrm{side}$ ) or their vehicle (Veh) $1 \mathrm{~h}$ before the fear memory test/extinction training. They received three consecutive extinction retrieval sessions (extinction retrieval 1,2 , and 3) on days $9-11$. On day 12 , rats were given unsignaled foot shocks and the following day tested for fear reinstatement (day 13). $\boldsymbol{B}-\boldsymbol{E}$, Injection of the NMDA+AMPA/kainate receptor antagonists did not block the impairing effects of intra-BLA FAAH overexpression on conditioned fear expression, but did induce impairing effects on behavioral performance at extinction training by itself. The same treatment did not affect fear reinstatement. $\boldsymbol{B}-\boldsymbol{E}$, Percentage freezing during cued fear conditioning $(\boldsymbol{B})$, extinction training $(\boldsymbol{C})$, extinction retrieval 1 (D), and extinction retrieval 3 and fear reinstatement test (E). Data are expressed as mean \pm SEM $\left(n=8-10\right.$ per group). ${ }^{*} p<0.05,{ }^{* * * *} p<0.0001$ versus the corresponding HSV-GFP-FAAH-Veh group. $\downarrow \bullet p<0.001$ versus the corresponding HSV-GFP-DAP5 + DNQX group. $\wedge \wedge \wedge \wedge p<0.0001$ versus the corresponding HSV-GFP-FAAH-DAP5 + DNQX group. $\bigcirc p<0.01$ versus the corresponding extinction retrieval 3 groups.

0.32, $p=0.93$, respectively; Fig. $6 B$ ). There was no difference between the groups in pre-CS freezing during the fearconditioning session (HSV effect: $F_{(1,51)}=0.09, p=0.77$; drug effect: $F_{(1,51)}=0.0001, p=0.99$; HVS $\times$ drug interaction effect: $F_{(1,51)}=0.08, p=0.78$; Fig. $\left.6 B\right)$, thus showing that all groups correctly acquired the CS-US association and did not present unconditioned freezing to the context. Repeated-measures ANOVA for freezing during CS presentations at extinction training did not reveal a significant treatment effect $\left(F_{(3,51)}=2.34, p=\right.$ 0.08; Fig. $6 C)$, but did show significant CS presentation and CS presentation $\times$ treatment interaction effects $\left(F_{(3,153)}=35.63\right.$, $p<0.0001 ; F_{(9,153)}=3.28, p=0.001$, respectively; Fig. $\left.6 C\right)$. Confirming our previous results, post hoc analyses showed that the HSV-GFP-FAAH group given vehicle injections presented significantly lower freezing levels during CS 1-5 than the HSVGFP-Veh group ( $p<0.0001$; Fig. $6 C$ ). Furthermore, within the HSV-GFP-FAAH group rats given vehicle showed significantly less freezing at CS $1-5$ than rats given BIC (HSV-GFP-FAAHBIC); $p<0.05$; Fig. $6 C$ ). There were no significant differences between the HSV-GFP-FAAH-BIC group and the two HSVGFP-injected groups given either vehicle or BIC. Analyses of percentage freezing during the pre-CS period showed no significant effects of HSV, drug, or HSV $\times$ drug interaction $\left(F_{(1,51)}=1.11\right.$, $p=0.30 ; F_{(1,51)}=0.02, p=0.90 ; F_{(1,51)}=0.30, p=0.59$, respectively; Fig. $6 C$ ). These results show that intra-BLA antagonism of $\mathrm{GABA}_{\mathrm{A}}$ receptors completely blocked the effects of FAAH overexpression on fear memory retrieval without affecting freezing behavior itself. Repeated-measures ANOVA for freezing during extinction retrieval 1 revealed significant CS presentation $\left(F_{(4,204)}=\right.$ 8.00, $p<0.0001$; Fig. $6 D)$ and treatment $\left(F_{(3,51)}=3.13, p=0.03\right.$; Fig. $6 D)$ effects, but no significant interaction between both factors $\left(F_{(12,204)}=1.06, p=0.39\right.$; Fig. $\left.6 D\right)$. Consistent with what we found in the previous experiments, post hoc comparisons revealed that the HSV-GFP-FAAH-Veh group expressed lower freezing levels at the first two CS presentations (CS 1 and 2) relative to the HSV-GFP-Veh control group ( $p<0.05$; Fig. $6 D$ ), confirming again that the FAAH overexpression decreased fear expression. There were no significant differences between the HSV-GFP-Veh and the HSV-GFP-BIC groups or between the HSV-GFP-Veh and the HSV-GFP-FAAH-BIC groups, indicating that subthreshold doses of BIC given to rats, which did not affect fear expression or extinction on its own, rendered freezing of animals with FAAH overexpression in the BLA comparable to those shown by control (HSV-GFP-Veh) animals.

All four experimental groups extinguished the fear memory, as shown by their decreased freezing levels when tested for extinction retrieval 2 and 3. Specifically, two-way ANOVA for total freezing during the $5 \mathrm{CS}$ presentations at extinction retrieval 2 revealed no significant $\operatorname{HSV}\left(F_{(1,51)}=0.35, p=0.56\right)$, drug $\left(F_{(1,51)}=0.11, p=0.74\right)$, or HSV $\times$ drug interaction effects $\left(F_{(1,51)}=0.92, p=0.34\right.$; percentage freezing for HSV-GFP-Veh: $16.92 \pm 5.79$, HSV-GFP-BIC: $11.33 \pm 4.09$, HSV-GFP-FAAHVeh: $10.18 \pm 2.31$, HSV-GFP-FAAH-BIC: $12.92 \pm 3.48)$. Similarly, two-way ANOVA for total freezing during the $5 \mathrm{CS}$ presentations at extinction retrieval 3 revealed no significant $\operatorname{HSV}\left(F_{(1,51)}=0.06, p=0.81\right), \operatorname{drug}\left(F_{(1,51)}=0.007, p=0.93\right)$, or $\mathrm{HSV} \times$ drug interaction effects $\left(F_{(1,51)}=0.44, p=0.51\right.$; Fig. $\left.6 E\right)$. After fear memory extinction had successfully occurred in all groups, rats were fear reinstated and tested for fear reinstatement to the CS the day after. Repeated-measures ANOVA for total freezing during CS presentations at extinction retrieval 3 and test for reinstatement revealed a significant time of test effect $\left(F_{(1,51)}=\right.$ 91.36, $p<0.0001$; Fig. $6 E)$, but no effects of treatment or interaction between both factors $\left(F_{(3,51)}=0.50, p=0.68 ; F_{(3,51)}=\right.$ $0.28, p=0.84$, respectively; Fig. $6 E$ ). All groups of rats showed increased freezing to the CS presentations $24 \mathrm{~h}$ after fear reinstatement relative to their last extinction retrieval session $(p<$ 0.001, for the HSV-GFP-Veh and HSV-GFP-FAAH-BIC groups; 
$p<0.0001$, for the remaining groups; Fig. $6 E$ ). Collectively, the finding that the $\mathrm{GABA}_{\mathrm{A}}$ antagonism completely blocked the effects of FAAH overexpression on conditioned fear expression and fear memory retrieval indicates that the effects of FAAH overexpression and reduction in AEA signaling involve GABAergic transmission in the BLA.

\section{Intra-BLA NMDA and AMPA/kainate receptor antagonism does not revert the detrimental effects of FAAH overexpression on conditioned fear expression and fear memory retrieval}

Because AEA signaling at CB1R in the BLA modulates the release of GABA and glutamate (Azad et al., 2004; Shin et al., 2010; Gunduz-Cinar et al., 2016), to rule out the possibility that AEA depletion in the condition of FAAH overexpression might have altered glutamate signaling and subsequently impaired learned fear expression and retrieval, we performed an additional experiment. Rats were tested in the same behavioral paradigm as the one used for the previous experiment except that half of the rats were given intra-BLA injections of the NMDA receptor antagonist D-AP5 (5 $\mu \mathrm{g})$ together with the AMPA/kainate receptor antagonist DNQX $(1 \mu \mathrm{g}) 1 \mathrm{~h}$ before the extinction training session (DAP5+DNQX, $5 \mu \mathrm{g}+1 \mu \mathrm{g} /$ side).

As shown in Figure $7 B$, repeated-measures ANOVA for percentage of freezing during CS-US presentations at conditioning revealed a significant CS-US presentation effect $\left(F_{(2,60)}=113.4\right.$, $p<0.0001$; Fig. $7 B$ ), but no treatment or CS-US presentation $\times$ treatment interaction effects $\left(F_{(3,30)}=2.11, p=0.12 ; F_{(6,60)}=\right.$ $1.27, p=0.29$, respectively; Fig. $7 B$ ). There were no differences between the groups in pre-CS freezing during the fear conditioning session (HSV effect: $F_{(1,30)}=0.02, p=0.90$; drug effect: $F_{(1,30)}=$ $1.60, p=0.22$; HSV $\times$ drug interaction effect: $F_{(1,30)}=1.23, p=$ 0.28 ; Fig. $7 B$ ), thus showing that all groups correctly acquired the CS-US association and did not present unconditioned freezing to the context. Repeated-measures ANOVA for freezing during CS presentations at extinction training revealed a significant treatment effect $\left(F_{(3,30)}=8.43, p=0.0003\right.$; Fig. $\left.7 C\right)$, a significant CS presentation effect $\left(F_{(3,90)}=34.24, p<0.0001\right)$, and a significant interaction between factors $\left(F_{(9,90)}=2.76, p=0.007\right.$; Fig. $\left.7 C\right)$. Confirming our previous results, post hoc analyses showed that the HSV-GFP-FAAH group given vehicle injections presented significantly lower freezing levels during CS 1-5 than the HSVGFP-Veh group $(p<0.0001$; Fig. $7 C)$. Furthermore, both HSV-GFP and HSV-GFP-FAAH groups given D-AP5+DNQX (HSV-GFP-DAP5+DNQX, HSV-GFP-FAAH-DAP5+DNQX) showed significantly less freezing at CS $1-5$ than control HSVGFP rats given vehicle $(p<0.001, p<0.0001$, respectively; Fig. $7 C)$, indicating that glutamate antagonism did not revert the impairing effects of FAAH overexpression and that the same treatment also impaired behavioral performance of rats given the control virus. Analyses of percentage freezing during the pre-CS period showed no significant effects of HSV, drug, or HSV $\times$ drug interaction $\left(F_{(1,30)}=1.39, p=0.25 ; F_{(1,30)}=0.30, p=0.59\right.$; $F_{(1,30)}=0.12, p=0.73$, respectively; Fig. $\left.7 C\right)$. Repeated-measures ANOVA for freezing during extinction retrieval 1 revealed a significant CS presentation effect $\left(F_{(4,120)}=5.86, p=0.0002\right.$; Fig. $7 D)$, but no treatment $\left(F_{(3,30)}=2.65, p=0.07\right.$; Fig. $\left.7 D\right)$ or $C S$ presentation $\times$ treatment effects $\left(F_{(12,120)}=0.72, p=0.73\right.$; Fig. $7 D)$. Consistent with what we found in the previous experiments, post hoc comparisons revealed that the HSV-GFP-FAAH-Veh group expressed lower freezing levels at the first CS presentation (CS 1) relative to the HSV-GFP-Veh control group $(p<0.05$; Fig. $7 D)$, confirming again that the FAAH overexpression de- creased fear expression. There were no significant differences among all the other groups.

All four experimental groups extinguished fear memory, as shown by their decreased freezing levels when tested for extinction retrieval 2 and 3. Specifically, two-way ANOVA for total freezing during the $5 \mathrm{CS}$ presentations at extinction retrieval 2 revealed a significant $\operatorname{HSV}\left(F_{(1,30)}=5.44, p=0.03\right)$, but no drug $\left(F_{(1,30)}=0.85, p=0.36\right)$ or HSV $\times$ drug interaction effects $\left(F_{(1,30)}=0.85, p=0.36\right.$; percentage freezing for HSV-GFP-Veh: $23.00 \pm 5.24$, HSV-GFP-DAP5+DNQX: $15.20 \pm 3.70$, HSV-GFPFAAH-Veh: $9.25 \pm 3.05$, HSV-GFP-FAAH-DAP5+DNQX: $9.25 \pm 4.66)$. Bonferroni post hoc test did not reveal any significant difference among groups. Similarly, two-way ANOVA for total freezing during the 5 CS presentations at extinction retrieval 3 revealed no significant $\operatorname{HSV}\left(F_{(1,30)}=3.09, p=0.09\right)$, drug $\left(F_{(1,30)}=0.18, p=0.67\right)$ or HSV $\times$ drug interaction effects $\left(F_{(1,30)}=0.07, p=0.80\right.$; Fig. $\left.7 E\right)$. After fear memory extinction had successfully occurred in all groups, rats were fear reinstated and tested for fear reinstatement to the CS the day after. Repeated-measures ANOVA for total freezing during CS presentations at extinction retrieval 3 and test for reinstatement revealed a significant time of test effect $\left(F_{(1,30)}=74.40, p<0.0001\right.$; Fig. $7 E$ ), but no effects of treatment or interaction between both factors $\left(F_{(3,30)}=0.74, p=0.54 ; F_{(3,30)}=0.79, p=0.51\right.$, respectively; Fig. 7E). All groups of rats showed increased freezing to the $\mathrm{CS}$ presentations $24 \mathrm{~h}$ after fear reinstatement relative to their last extinction retrieval session $(p<0.0001$, for the HSV-GFP-Veh group; $p<0.001$, for the HSV-GFP-FAAH-Veh group; $p<0.01$, for the remaining groups; Fig. $7 E$ ). Collectively, the finding that the administration of a mixture of antagonists to ionotropic glutamate receptors (NMDA+AMPA/kainate) did not block the effects of FAAH overexpression on conditioned fear expression and fear memory retrieval indicates that the effects of AEA depletion do not involve an elevation in glutamatergic transmission in the BLA.

\section{Discussion}

Previous studies have reported that increased BLA AEA signaling attenuates stress responses, anxiety and fear expression (for review, see Ramikie and Patel, 2012; Gunduz-Cinar et al., 2013a; Morena et al., 2016b). We show here for the first time that viral-mediated FAAH overexpression in BLA pyramidal neurons decreases AEA levels and this reduction attenuates neuroendocrine stress response, decreases anxiety-like behavior, and promotes suppression of conditioned fear, likely through increased GABAergic transmission.

Consistent with previous studies (Cole et al., 2012; Yiu et al., 2014), the HSV vector that we used predominately resulted in transfection within BLA pyramidal neurons. Because FAAH is normatively and primarily expressed in the majority of BLA pyramidal neurons (Gulyas et al., 2004), our approach allowed us to examine the impact of FAAH overexpression within the appropriate cell population that is already FAAH-positive without resulting in ectopic expression within neuronal subtypes that do not natively express this enzyme. Furthermore, the GFP-FAAH vector rapidly produced a significant increase in AEA hydrolysis and reduced AEA content, but not 2-AG, relative to the GFP alone vector. Previous work has shown that a lentiviral vector used to overexpress FAAH robustly altered both FAAH activity and AEA content by itself (Rubino et al., 2008). Importantly, our control studies demonstrated that the HSV vector itself did not affect FAAH activity or endocannabinoid content. Contrary to the usage of adeno-associated viral vectors to overexpress FAAH 
Resting conditions

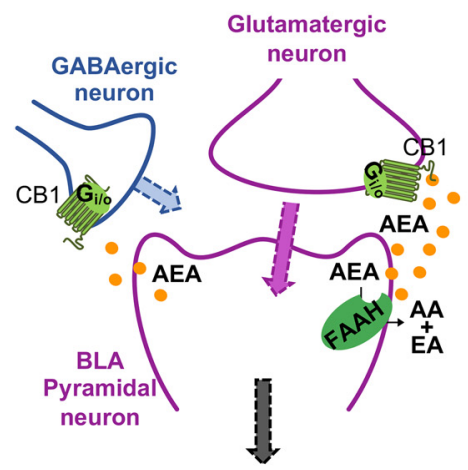

Stress

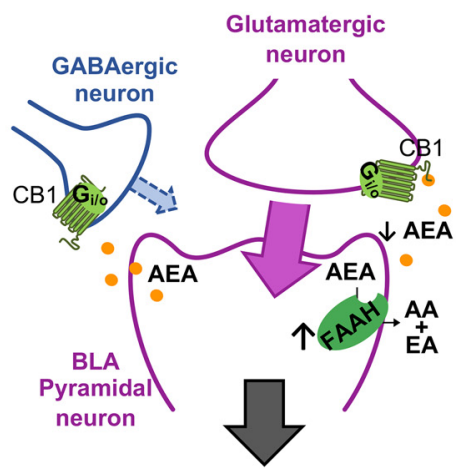

FAAH overexpression

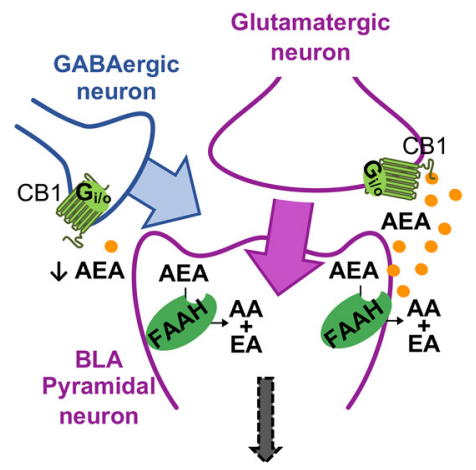

Figure 8. Putative model of AEA role in the modulation of excitatory/inhibitory inputs onto BLA pyramidal neurons under resting, stress, and FAAH overexpression conditions. Under resting basal conditions, tonic AEA signaling regulates the inhibitory/excitatory balance in the BLA by activating CB1Rs on both GABAergic interneurons and glutamatergic neurons projecting to BLA pyramidal neurons. Following exposure to stress, increased FAAH activity reduces AEA signaling at glutamatergic synapses, which then results in a facilitation of glutamate release and subsequent activation of excitatory pyramidal projection neurons of the BLA to drive stress-related behavioral responses. HSV-mediated FAAH overexpression might result in a selective deficit of AEA signaling at CB1Rs at GABAergic synapses, thus disinhibiting GABA release, which would in turn lead to increased inhibition of BLA pyramidal projection neurons and reduce behavioral indices of stress, anxiety, and fear.

(Zimmermann et al., 2018), the HSV vector that we used induced a rapid and transient expression of FAAH, which allowed us to examine the effects of AEA depletion in a restricted time window on specific memory phases.

We and others have previously established that stress exposure results in a FAAH-mediated decline in amygdala AEA signaling, which is thought to contribute to activation of BLA pyramidal neurons and promote activation of the HPA axis, development of anxiety, and impairments in fear extinction (Patel et al., 2005; Rademacher et al., 2008; Ganon-Elazar and Akirav, 2009; Hill et al., 2009; Bedse et al., 2014; Gray et al., 2015). Based on these data, we had predicted that intra-BLA FAAH overexpression and depletion of AEA signaling would have recapitulated the neuroendocrine and behavioral effects of stress. Unexpectedly, we found that FAAH overexpression induced an overall decrease in stress-induced elevations in plasma corticosterone levels measured during a $90 \mathrm{~min}$ time course after acute stress exposure. Consistently, reductions in BLA AEA signaling also reliably reduced indices of anxiety across different behavioral tasks (EPM and LD box). Importantly, our manipulation did not alter locomotor activity because we found no differences between treatment conditions in the number of closed arm entries in the EPM $48 \mathrm{~h}$ after HSV injection and in the distance traveled in the OF $72 \mathrm{~h}$ after HSV injection. Therefore, intra-BLA FAAH overexpression produced a blunted stress response and an anxiolytic phenotype.

AEA signaling, particularly within the BLA, has been shown to suppress fear behavior and to promote fear extinction (Marsicano et al., 2002; Chhatwal et al., 2005; Ganon-Elazar and Akirav, 2009; Gunduz-Cinar et al., 2013b; Llorente-Berzal et al., 2015). Therefore, we next examined the impact of reducing BLA AEA signaling on fear memory retrieval and extinction. Because fear memories become independent of the BLA 1 week after conditioning (Do-Monte et al., 2015), the use of HSV vectors that produce rapid and maximal novel protein expression within 48-72 h (Barrot et al., 2002) allowed us to perform fear conditioning in a naive state and then examine how FAAH overexpression specifically affected fear memory retrieval and extinction. Interestingly, contrary to our expectations, FAAH overexpression induced a dramatic and highly replicable reduction of conditioned fear expression and memory. This robust effect was maintained after cannulation surgery. Indeed, rats showed the same reduction in freezing behavior when they were given HSV either through surgical microinjection $24 \mathrm{~h}$ after conditioning or through their cannulae implanted 10-12 d before conditioning. This effect was not due to a general impairment in the expression of fear behavior because we showed that virus injection before conditioning did not affect fear conditioning itself or the ability to show conditional freezing during extinction training and retrieval. Gene expression following HSV injection dissipates within 1 week after injection (Carlezon et al., 1997; Barrot et al., 2002); therefore, it is likely that, for rats injected before fear conditioning, the effects of the virus had faded during the extinction training session ( $4 \mathrm{~d}$ after conditioning and 1 week after virus injection), when rats were able to show freezing behavior. This provides further evidence that our manipulation does not affect the acquisition of fear, but rather, the selective expression of learned fear and fear memory recall. Similarly, for the remaining experiments examining the effects of FAAH overexpression on conditioned fear expression/recall (i.e., virus injection $72 \mathrm{~h}$ before extinction training), it is likely that the effects of HSV had dissipated following the last extinction retrieval session. Moreover, all treatment groups showed freezing behavior upon fear reinstatement. The specificity of these effects to FAAH overexpression was also confirmed by the fact that intra-BLA injections of the FAAH inhibitor URB597 $1 \mathrm{~h}$ before extinction training completely counteracted the conditioned fear-suppressing effects and impairment in memory retrieval induced by FAAH overexpression. Therefore, these data clearly demonstrate that intra-BLA FAAH overexpression results in a select yet robust reduction of fear memory retrieval.

Within the BLA, FAAH expression seems to be restricted to pyramidal neurons (Gulyas et al., 2004) and AEA has been shown to regulate the inhibitory/excitatory balance in these neurons by inhibiting the afferent release of GABA and glutamate (Azad et al., 2004; Shin et al., 2010; Gunduz-Cinar et al., 2016) through activation of CB1R expressed on GABAergic interneurons (Katona et al., 2001) and glutamatergic neurons impinging on BLA pyramidal cells (Domenici et al., 2006; Kodirov et al., 2010; Shin et al., 2010). Furthermore, CB1R activation, depending on whether it is expressed on GABAergic interneurons versus glutamatergic cortical neurons, may exert anxiogenic or anxiolytic effects and promote or reduce fear-related behaviors, respectively (Kamprath et al., 2009; Lafenêtre et al., 2009; Metna-Laurent et al., 2012; Rey et al., 2012; Llorente-Berzal et al., 2015). Therefore, 
FAAH activity, by determining AEA concentration at active synapses (Blankman and Cravatt, 2013), could modulate presynaptic glutamate (Domenici et al., 2006; Kodirov et al., 2010; Shin et al., 2010) and GABA release (Azad et al., 2004; Gunduz-Cinar et al., 2013b, 2016). Under resting conditions, tonic AEA signaling at CB1R may balance GABAergic and glutamatergic transmission in the BLA. Indeed, acute disruption of BLA CB1R signaling increases synaptic GABA release (Varodayan et al., 2017). Because the phenotype produced by FAAH overexpression paralleled what has been reported following elevations in GABAergic signaling in the BLA (Bueno et al., 2005; Akirav et al., 2006; Rea et al., 2011) and is consistent with what would be expected from a loss of CB1R signaling on GABAergic neurons (Kamprath et al., 2009; Lafenêtre et al., 2009; Metna-Laurent et al., 2012; Rey et al., 2012; Llorente-Berzal et al., 2015), we hypothesized that FAAH overexpression induced a loss of AEA inhibitory signaling at CB1R on GABAergic terminals and augmented GABA release. Consistent with this prediction, local administration of a $\mathrm{GABA}_{\mathrm{A}}$ receptor antagonist reversed the memory impairing effects of FAAH overexpression. Moreover, NMDA and AMPA/kainate receptor antagonism into the BLA did not prevent the effects of FAAH overexpression on learned fear expression, but did reduce fear expression and retrieval in control rats by itself, consistently with previous reports (Barros et al., 2000; Lee et al., 2001). These results suggest that intra-BLA FAAH overexpression likely resulted in a selective deficit in AEA signaling at CB1Rs at GABAergic synapses, thus disinhibiting GABA release and shifting the excitatory/inhibitory balance onto BLA pyramidal neurons, favoring inhibition of these neurons (Fig. 8). Similarly, intra-BLA administration of a CB1R antagonist has been shown to impair fear memory reconsolidation through increased GABAergic transmission (Ratano et al., 2014), suggesting that our data are consistent with a putative model of tonic endocannabinoid regulation of GABA release as being a mediator of altered cognitive processes. Accordingly, optogenetic and pharmacological studies have demonstrated that inhibition of neural activity in BLA pyramidal neurons reduces behavioral indices of stress, anxiety, and fear (Nagy et al., 1979; Helmstetter, 1993; Harris and Westbrook, 1995; Sanders and Shekhar, 1995; Tye et al., 2011).

Apparently contrary to our findings, previous work from us, and others has suggested that stress-induced release of corticotropin-releasing hormone $(\mathrm{CRH})$ and activation of CRH receptor-1 (CRHR1) reduces amygdala AEA signaling at glutamatergic synapses, which then favors feedforward activation of amygdala neurons to generate anxiety (Gray et al., 2015, 2016; Bedse et al., 2017; Natividad et al., 2017). It is likely that CRHR1 and the pool of FAAH that these receptors activate to deplete AEA signaling are predominately localized around excitatory as opposed to inhibitory synapses. Consistent with this model, in the central amygdala, CRHR1 is found predominately clustered around excitatory synapses (Treweek et al., 2009). However, given the lack of understanding of the molecular neuroanatomy of these proteins in the BLA, how FAAH overexpression may preferentially affect GABAergic over glutamatergic synapses remains to be determined. The possibility exists that altered AEA tone at non-GABAergic or non-glutamatergic terminals (such as noradrenergic, dopaminergic, and serotonergic inputs to the BLA) might be involved in the detrimental effects of FAAH overexpression on fear memory recall and expression.

Here, we show that AEA deficiency in BLA pyramidal neurons leads to a general suppression of stress-related neuroendocrine and emotional outcomes and reduction in conditioned fear ex- pression and memory, unveiling an important role for optimal AEA signaling within the BLA to orchestrate a proper behavioral response to challenge. We suggest that this effect is mediated by a loss of AEA signaling at CB1Rs on GABAergic neurons; however, we cannot rule out the possibility that it could be due to a loss of AEA signaling at other neuronal populations (noradrenergic, dopaminergic, serotonergic) or other receptor targets such as transient receptor potential vanilloid-1 (TRPV1) or that it involves changes in other FAAH substrates beyond AEA. These alternate mechanisms, however, are less likely given that blockade of TRPV1 before extinction training does not affect fear memory expression (Llorente-Berzal et al., 2015) and there is no evidence to date that any other substrates of FAAH modulate BLA GABAergic neurotransmission. Our data suggest that BLA AEA signaling may influence stress responsivity, emotional behavior, and fear memory processes in an inverted U-shaped fashion dependent on its ability to modulate neurotransmission possibly via CB1Rs on different neuronal populations. A recent study found that overexpression of FAAH within pyramidal neurons in the hippocampus produced an elevation in anxiety and glutamatergic transmission (Zimmerman et al., 2018), although FAAH overexpression was not restricted to a specific time window. This suggests that AEA signaling very dynamically regulates emotional behavior through both region- and synapse-specific mechanisms. Understanding how AEA regulates anxiety and fear memory may provide insight into psychiatric conditions such as posttraumatic stress disorder and help to elucidate the mechanisms by which FAAH-based pharmacological tools that are currently being explored for the treatment of these disorders may exert their therapeutic effects.

\section{References}

Akirav I, Raizel H, Maroun M (2006) Enhancement of conditioned fear extinction by infusion of the GABA A agonist muscimol into the rat prefrontal cortex and amygdala. Eur J Neurosci 23:758-764. CrossRef Medline

Azad SC, Monory K, Marsicano G, Cravatt BF, Lutz B, Zieglgänsberger W, Rammes G (2004) Circuitry for associative plasticity in the amygdala involves endocannabinoid signaling. J Neurosci 24:9953-9961. CrossRef Medline

Bambico FR, Cassano T, Dominguez-Lopez S, Katz N, Walker CD, Piomelli D, Gobbi G (2010) Genetic deletion of fatty acid amide hydrolase alters emotional behavior and serotonergic transmission in the dorsal raphe, prefrontal cortex, and hippocampus. Neuropsychopharmacology 35: 2083-2100. CrossRef Medline

Barros DM, Izquierdo LA, Mello e Souza T, Ardenghi PG, Pereira P, Medina JH, Izquierdo I (2000) Molecular signalling pathways in the cerebral cortex are required for retrieval of one-trial avoidance learning in rats. Behav Brain Res 114:183-192. CrossRef Medline

Barrot M, Olivier JD, Perrotti LI, DiLeone RJ, Berton O, Eisch AJ, Impey S, Storm DR, Neve RL, Yin JC, Zachariou V, Nestler EJ (2002) CREB activity in the nucleus accumbens shell controls gating of behavioral responses to emotional stimuli. Proc Natl Acad Sci U S A 99:11435-11440. CrossRef Medline

Bedse G, Colangeli R, Lavecchia AM, Romano A, Altieri F, Cifani C, Cassano T, Gaetani S (2014) Role of the basolateral amygdala in mediating the effects of the fatty acid amide hydrolase inhibitor URB597 on HPA axis response to stress. Eur Neuropsychopharmacol 24:1511-1523. CrossRef Medline

Bedse G, Romano A, Tempesta B, Lavecchia MA, Pace L, Bellomo A, Duranti A, Micioni Di Bonaventura MV, Cifani C, Cassano T, GaetaniS (2015) Inhibition of anandamide hydrolysis enhances noradrenergic and GABAergic transmission in the prefrontal cortex and basolateral amygdala of rats subjected to acute swim stress. J Neurosci Res 93:777-787. CrossRef Medline

Bedse G, Hartley ND, Neale E, Gaulden AD, Patrick TA, Kingsley PJ, Uddin MJ, Plath N, Marnett LJ, Patel S (2017) Functional redundancy between canonical endocannabinoid signaling systems in the modulation of anxiety. Biol Psychiatry 82:488-499. CrossRef Medline

Bitencourt RM, Pamplona FA, Takahashi RN (2008) Facilitation of contex- 
tual fear memory extinction and anti-anxiogenic effects of AM404 and cannabidiol in conditioned rats. Eur Neuropsychopharmacol 18:849859. CrossRef Medline

Blankman JL, Cravatt BF (2013) Chemical probes of endocannabinoid metabolism. Pharmacol Rev 65:849-871. CrossRef Medline

Bortolato M, Campolongo P, Mangieri RA, Scattoni ML, Frau R, Trezza V, La Rana G, Russo R, Calignano A, Gessa GL, Cuomo V, Piomelli D (2006) Anxiolytic-like properties of the anandamide transport inhibitor AM404. Neuropsychopharmacology 31:2652-2659. CrossRef Medline

Bueno CH, Zangrossi H Jr, Viana MB (2005) The inactivation of the basolateral nucleus of the rat amygdala has an anxiolytic effect in the elevated T-maze and light/dark transition tests. Braz J Med Biol Res 38:1697-1701. CrossRef Medline

Carlezon WA Jr, Boundy VA, Haile CN, Lane SB, Kalb RG, Neve RL, Nestler EJ (1997) Sensitization to morphine induced by viral-mediated gene transfer. Science 277:812-814. CrossRef Medline

Chhatwal JP, Davis M, Maguschak KA, Ressler KJ (2005) Enhancing cannabinoid neurotransmission augments the extinction of conditioned fear. Neuropsychopharmacology 30:516-524. CrossRef Medline

Colangeli R, Pierucci M, Benigno A, Campiani G, Butini S, Di Giovanni G (2017) The FAAH inhibitor URB597 suppresses hippocampal maximal dentate afterdischarges and restores seizure-induced impairment of short and long-term synaptic plasticity. Sci Rep 7:11152. CrossRef Medline

Cole CJ, Mercaldo V, Restivo L, Yiu AP, Sekeres MJ, Han JH, Vetere G, Pekar T, Ross PJ, Neve RL, Frankland PW, Josselyn SA (2012) MEF2 negatively regulates learning-induced structural plasticity and memory formation. Nat Neurosci 15:1255-1264. CrossRef Medline

Dincheva I, Drysdale AT, Hartley CA, Johnson DC, Jing D, King EC, Ra S, Gray JM, Yang R, DeGruccio AM, Huang C, Cravatt BF, Glatt CE, Hill MN, Casey BJ, Lee FS (2015) FAAH genetic variation enhances frontoamygdala function in mouse and human. Nat Commun 6:6395. CrossRef Medline

Domenici MR, Azad SC, Marsicano G, Schierloh A, Wotjak CT, Dodt HU, Zieglgänsberger W, Lutz B, Rammes G (2006) Cannabinoid receptor type 1 located on presynaptic terminals of principal neurons in the forebrain controls glutamatergic synaptic transmission. J Neurosci 26:57945799. CrossRef Medline

Do-Monte FH, Quinõnes-Laracuente K, Quirk GJ (2015) A temporal shift in the circuits mediating retrieval of fear memory. Nature 519:460-463. CrossRef Medline

Dono LM, Currie PJ (2012) The cannabinoid receptor CB1 inverse agonist AM251 potentiates the anxiogenic activity of urocortin I in the basolateral amygdala. Neuropharmacology 62:192-199. CrossRef Medline

Ganon-Elazar E, Akirav I (2009) Cannabinoid receptor activation in the basolateral amygdala blocks the effects of stress on the conditioning and extinction of inhibitory avoidance. J Neurosci 29:11078-11088. CrossRef Medline

Gray JM, Vecchiarelli HA, Morena M, Lee TT, Hermanson DJ, Kim AB, McLaughlin RJ, Hassan KI, Kühne C, Wotjak CT, Deussing JM, Patel S, Hill MN (2015) Corticotropin-releasing hormone drives anandamide hydrolysis in the amygdala to promote anxiety. J Neurosci 35:3879-3892. CrossRef Medline

Gray JM, Wilson CD, Lee TT, Pittman QJ, Deussing JM, Hillard CJ, McEwen BS, Schulkin J, Karatsoreos IN, Patel S, Hill MN (2016) Sustained glucocorticoid exposure recruits cortico-limbic CRH signaling to modulate endocannabinoid function. Psychoneuroendocrinology 66:151-158. CrossRef Medline

Gulyas AI, Cravatt BF, Bracey MH, Dinh TP, Piomelli D, Boscia F, Freund TF (2004) Segregation of two endocannabinoid-hydrolyzing enzymes into pre- and after synaptic compartments in the rat hippocampus, cerebellum and amygdala. Eur J Neurosci 20:441-458. CrossRef Medline

Gunduz-Cinar O, Hill MN, McEwen BS, Holmes A (2013a) Amygdala FAAH and anandamide: mediating protection and recovery from stress. Trends Pharmacol Sci 34:637-644. CrossRef Medline

Gunduz-Cinar O, MacPherson KP, Cinar R, Gamble-George J, Sugden K, Williams B, Godlewski G, Ramikie TS, Gorka AX, Alapafuja SO, Nikas SP, Makriyannis A, Poulton R, Patel S, Hariri AR, Caspi A, Moffitt TE, Kunos G, Holmes A (2013b) Convergent translational evidence of a role for anandamide in amygdala-mediated fear extinction, threat processing and stress-reactivity. Mol Psychiatry 18:813-823. CrossRef Medline

Gunduz-Cinar O, Flynn S, Brockway E, Kaugars K, Baldi R, Ramikie TS, Cinar R, Kunos G, Patel S, Holmes A (2016) Fluoxetine facilitates fear extinction through amygdala endocannabinoids. Neuropsychopharmacology 41:1598-1609. CrossRef Medline

Han JH, Kushner SA, Yiu AP, Hsiang HL, Buch T, Waisman A, Bontempi B, Neve RL, Frankland PW, Josselyn SA (2009) Selective erasure of a fear memory. Science 323:1492-1496. CrossRef Medline

Hariri AR, Gorka A, Hyde LW, Kimak M, Halder I, Ducci F, Ferrell RE, Goldman D, Manuck SB (2009) Divergent effects of genetic variation in endocannabinoid signaling on human threat- and reward-related brain function. Biol Psychiatry 66:9-16. CrossRef Medline

Harris JA, Westbrook RF (1995) Effects of benzodiazepine microinjection into the amygdala or periaqueductal gray on the expression of conditioned fear and hypoalgesia in rats. Behav Neurosci 109:295-304. CrossRef Medline

Helmstetter FJ (1993) Stress-induced hypoalgesia and defensive freezing are attenuated by application of diazepam to the amygdala. Pharmacol Biochem Behav 44:433-438. CrossRef Medline

Hill MN, McLaughlin RJ, Morrish AC, Viau V, Floresco SB, Hillard CJ, Gorzalka BB (2009) Suppression of amygdalar endocannabinoid signaling by stress contributes to activation of the hypothalamic-pituitary-adrenal axis. Neuropsychopharmacology 34:2733-2745. CrossRef Medline

Hill MN, Karatsoreos IN, Hillard CJ, McEwen BS (2010) Rapid elevations in limbic endocannabinoid content by glucocorticoid hormones in vivo. Psychoneuroendocrinology 35:1333-1338. CrossRef Medline

Hillard CJ, Beatka M, Sarvaideo J (2016) Endocannabinoid signaling and the hypothalamic-pituitary-adrenal axis. Compr Physiol 7:1-15. CrossRef Medline

Holmes A, Rodgers RJ (2003) Prior exposure to the elevated plus-maze sensitizes mice to the acute behavioral effects of fluoxetine and phenelzine. Eur J Pharmacol 459:221-230. CrossRef Medline

Jenniches I, Ternes S, Albayram O, Otte DM, Bach K, Bindila L, Michel K, Lutz B, Bilkei-Gorzo A, Zimmer A (2016) Anxiety, stress, and fear response in mice with reduced endocannabinoid levels. Biol Psychiatry 79: 858-868. CrossRef Medline

Kalueff AV, Tuohimaa P (2005) The grooming analysis algorithm discriminates between different levels of anxiety in rats: potential utility for neurobehavioural stress research. J Neurosci Methods 143:169-177. CrossRef Medline

Kamprath K, Plendl W, Marsicano G, Deussing JM, Wurst W, Lutz B, Wotjak CT (2009) Endocannabinoids mediate acute fear adaptation via glutamatergic neurons independently of corticotropin-releasing hormone signaling. Genes Brain Behav 8:203-211. CrossRef Medline

Kanai K, Nunoya T, Shibuya K, Nakamura T, Tajima M (1998) Variations in effectiveness of antigen retrieval pretreatments for diagnostic immunohistochemistry. Res Vet Sci 64:57-61. CrossRef Medline

Kathuria S, Gaetani S, Fegley D, Valiño F, Duranti A, Tontini A, Mor M, Tarzia G, La Rana G, Calignano A, Giustino A, Tattoli M, Palmery M, Cuomo V, Piomelli D (2003) Modulation of anxiety through blockade of anandamide hydrolysis. Nat Med 9:76-81. CrossRef Medline

Katona I, Freund TF (2012) Multiple functions of endocannabinoid signaling in the brain. Annu Rev Neurosci 35:529-558. CrossRef Medline

Katona I, Rancz EA, Acsady L, Ledent C, Mackie K, Hajos N, Freund TF (2001) Distribution of CB1 cannabinoid receptors in the amygdala and their role in the control of GABAergic transmission. J Neurosci 21:95069518. CrossRef Medline

Kodirov SA, Jasiewicz J, Amirmahani P, Psyrakis D, Bonni K, Wehrmeister M, Lutz B (2010) Endogenous cannabinoids trigger the depolarizationinduced suppression of excitation in the lateral amygdala. Learn Mem 17:43-49. CrossRef Medline

Lafenêtre P, Chaouloff F, Marsicano G (2009) Bidirectional regulation of novelty-induced behavioral inhibition by the endocannabinoid system. Neuropharmacology 57:715-721. CrossRef Medline

Lee HJ, Choi JS, Brown TH, Kim JJ (2001) Amygdalar NMDA receptors are critical for the expression of multiple conditioned fear responses. J Neurosci 21:4116-4124. CrossRef Medline

Llorente-Berzal A, Terzian ALB, Di Marzo V, Micale V, Viveros MP, Wotjak CT (2015) 2-AG promotes the expression of conditioned fear via cannabinoid receptor type 1 on GABAergic neurons. Psychopharmacology (Berl) 232:2811-2825. CrossRef Medline

Lutz B, Marsicano G, Maldonado R, Hillard CJ (2015) The endocannabinoid system in guarding against fear, anxiety and stress. Nat Rev Neurosci 16:705-718. CrossRef Medline

Manduca A, Morena M, Campolongo P, Servadio M, Palmery M, Trabace L, 
Hill MN, Vanderschuren LJ, Cuomo V, Trezza V (2015) Distinct roles of the endocannabinoids anandamide and 2-arachidonoylglycerol in social behavior and emotionality at different developmental ages in rats. Eur Neuropsychopharmacol 25:1362-1374. CrossRef Medline

Marsicano G, Wotjak CT, Azad SC, Bisogno T, Rammes G, Cascio MG, Hermann H, Tang J, Hofmann C, Zieglgänsberger W, Di Marzo V, Lutz B (2002) The endogenous cannabinoid system controls extinction of aversive memories. Nature 418:530-534. CrossRef Medline

Mayo LM, Asratian A, Lindé J, Holm L, Nätt D, Augier G, Stensson N, Vecchiarelli HA, Balsevich G, Aukema RJ, Ghafouri B, Spagnolo PA, Lee FS, Hill MN, Heilig M (2018) Protective effects of elevated anandamide on stress and fear-related behaviors: translational evidence from humans and mice. Mol Psychiatry. Advance online publication. Retrieved August 17, 2018. doi: 10.1038/s41380-018-0215-1

Metna-Laurent M, Soria-Gómez E, Verrier D, Conforzi M, Jégo P, Lafenêtre P, Marsicano G (2012) Bimodal control of fear-coping strategies by $\mathrm{CB}_{1}$ cannabinoid receptors. J Neurosci 32:7109-7118. CrossRef Medline

Morena M, Campolongo P (2014) The endocannabinoid system: an emotional buffer in the modulation of memory function. Neurobiol Learn Mem 112:30-43. CrossRef Medline

Morena M, Roozendaal B, Trezza V, Ratano P, Peloso A, Hauer D, Atsak P, Trabace L, Cuomo V, McGaugh JL, Schelling G, Campolongo P (2014) Endogenous cannabinoid release within prefrontal-limbic pathways affects memory consolidation of emotional training. Proc Natl Acad Sci U S A 111:18333-18338. CrossRef Medline

Morena M, De Castro V, Gray JM, Palmery M, Trezza V, Roozendaal B, Hill MN, Campolongo P (2015) Training-associated emotional arousal shapes endocannabinoid modulation of spatial memory retrieval in rats. J Neurosci 35:13962-13974. CrossRef Medline

Morena M, Leitl KD, Vecchiarelli HA, Gray JM, Campolongo P, Hill MN (2016a) Emotional arousal state influences the ability of amygdalar endocannabinoid signaling to modulate anxiety. Neuropharmacology 111: 59-69. CrossRef Medline

Morena M, Patel S, Bains JS, Hill MN (2016b) Neurobiological interactions between stress and the endocannabinoid system. Neuropsychopharmacology 41:80-102. CrossRef Medline

Morena M, Berardi A, Colucci P, Palmery M, Trezza V, Hill MN, Campolongo P (2018) Enhancing endocannabinoid neurotransmission augments the efficacy of extinction training and ameliorates traumatic stressinduced behavioral alterations in rats. Neuropsychopharmacology 43: 1284-1296. CrossRef Medline

Nagy J, Zámbó K, Decsi L (1979) Anti-anxiety action op diazepam after intraamygdaloid application in the rat. Neuropharmacology 18:573-576. CrossRef Medline

Natividad LA, Buczynski MW, Herman MA, Kirson D, Oleata CS, Irimia C, Polis I, Ciccocioppo R, Roberto M, Parsons LH (2017) Constitutive increases in amygdalar corticotropin-releasing factor and fatty acid amide hydrolase drive an anxious phenotype. Biol Psychiatry 82:500-510. CrossRef Medline

Ogasawara D, Deng H, Viader A, Baggelaar MP, Breman A, den Dulk H, van den Nieuwendijk AM, Soethoudt M, van der Wel T, Zhou J, Overkleeft HS, Sanchez-Alavez M, Mori S, Nguyen W, Conti B, Liu X, Chen Y, Liu QS, Cravatt BF, van der Stelt M (2016) Rapid and profound rewiring of brain lipid signaling networks by acute diacylglycerol lipase inhibition. Proc Natl Acad Sci U S A 113:26-33. CrossRef Medline

Pamplona FA, Bitencourt RM, Takahashi RN (2008) Short- and long-term effects of cannabinoids on the extinction of contextual fear memory in rats. Neurobiol Learn Mem 90:290-293. CrossRef Medline

Park S, Kramer EE, Mercaldo V, Rashid AJ, Insel N, Frankland PW, Josselyn SA (2016) Neuronal allocation to a hippocampal engram. Neuropsychopharmacology 41:2987-2993. CrossRef Medline

Patel S, Roelke CT, Rademacher DJ, Hillard CJ (2005) Inhibition of restraint stress-induced neural and behavioural activation by endogenous cannabinoid signalling. Eur J Neurosci 21:1057-1069. CrossRef Medline

Paxinos G, Watson C (2004) The rat brain in stereotaxic coordinates, Ed 5. New York: Academic.

Qi M, Morena M, Vecchiarelli HA, Hill MN, Schriemer DC (2015) A robust capillary liquid chromatography/tandem mass spectrometry method for quantitation of neuromodulatory endocannabinoids. Rapid Commun Mass Spectrom 29:1889-1897. CrossRef Medline

Rademacher DJ, Meier SE, Shi L, Ho WS, Jarrahian A, Hillard CJ (2008)
Effects of acute and repeated restraint stress on endocannabinoid content in the amygdala, ventral striatum, and medial prefrontal cortex in mice. Neuropharmacology 54:108-116. CrossRef Medline

Ramikie TS, Patel S (2012) Endocannabinoid signaling in the amygdala: anatomy, synaptic signaling, behavior, and adaptations to stress. Neuroscience 204:38-52. CrossRef Medline

Ratano P, Everitt BJ, Milton AL (2014) The CB1 receptor antagonist AM251 impairs reconsolidation of Pavlovian fear memory in the rat basolateral amygdala. Neuropsychopharmacology 39:2529-2537. CrossRef Medline

Rea K, Roche M, Finn DP (2011) Modulation of conditioned fear, fearconditioned analgesia, and brain regional C-fos expression following administration of muscimol into the rat basolateral amygdala. J Pain 12: 712-721. CrossRef Medline

Rey AA, Purrio M, Viveros MP, Lutz B (2012) Biphasic effects of cannabinoids in anxiety responses: $\mathrm{CB} 1$ and GABA B receptors in the balance of gabaergic and glutamatergic neurotransmission. Neuropsychopharmacology 37:2624-2634. CrossRef Medline

Rodgers RJ, Cao BJ, Dalvi A, Holmes A (1997) Animal models of anxiety: an ethological perspective. Braz J Med Biol Res 30:289-304. CrossRef Medline

Rodgers RJ, Haller J, Holmes A, Halasz J, Walton TJ, Brain PF (1999) Corticosterone response to the plus-maze: high correlation with risk assessment in rats and mice. Physiol Behav 68:47-53. CrossRef Medline

Rubino T, Realini N, Castiglioni C, Guidali C, Viganó D, Marras E, Petrosino S, Perletti G, Maccarrone M, Di Marzo V, Parolaro D (2008) Role in anxiety behavior of the endocannabinoid system in the prefrontal cortex. Cereb Cortex 18:1292-1301. CrossRef Medline

Sanders SK, Shekhar A (1995) Regulation of anxiety by GABAA receptors in the rat amygdala. Pharmacol Biochem Behav 52:701-706. CrossRef Medline

Shi SR, Chaiwun B, Young L, Cote RJ, Taylor CR (1993) Antigen retrieval technique utilizing citrate buffer or urea solution for immunohistochemical demonstration of androgen receptor in formalin-fixed paraffin sections. J Histochem Cytochem 41:1599-1604. CrossRef Medline

Shin RM, Tully K, Li Y, Cho JH, Higuchi M, Suhara T, Bolshakov VY (2010) Hierarchical order of coexisting pre- and after synaptic forms of longterm potentiation at synapses in amygdala. Proc Natl Acad Sci U S A 107:19073-19078. CrossRef Medline

Shonesy BC, Bluett RJ, Ramikie TS, Báldi R, Hermanson DJ, Kingsley PJ, Marnett LJ, Winder DG, Colbran RJ, Patel S (2014) Genetic disruption of 2-arachidonoylglycerol synthesis reveals a key role for endocannabinoid signaling in anxiety modulation. Cell Rep 9:1644-1653. CrossRef Medline

Treweek JB, Jaferi A, Colago EE, Zhou P, Pickel VM (2009) Electron microscopic localization of corticotropin-releasing factor (CRF) and CRF receptor in rat and mouse central nucleus of the amygdala. J Comp Neurol 512:323-335. CrossRef Medline

Tye KM, Prakash R, Kim SY, Fenno LE, Grosenick L, Zarabi H, Thompson KR, Gradinaru V, Ramakrishnan C, Deisseroth K (2011) Amygdala circuitry mediating reversible and bidirectional control of anxiety. Nature 471:358-362. CrossRef Medline

Varodayan FP, Bajo M, Soni N, Luu G, Madamba SG, Schweitzer P, Roberto M (2017) Chronic alcohol exposure disrupts CB 1 regulation of GABAergic transmission in the rat basolateral amygdala. Addict Biol 22:766-778. CrossRef Medline

Vecchiarelli HA, Gandhi CP, Gray JM, Morena M, Hassan KI, Hill MN (2016) Divergent responses of inflammatory mediators within the amygdala and medial prefrontal cortex to acute psychological stress. Brain Behav Immun 51:70-91. CrossRef Medline

Yiu AP, Mercaldo V, Yan C, Richards B, Rashid AJ, Hsiang HL, Pressey J, Mahadevan V, Tran MM, Kushner SA, Woodin MA, Frankland PW, Josselyn SA (2014) Neurons are recruited to a memory trace based on relative neuronal excitability immediately before training. Neuron 83: 722-735. CrossRef Medline

Zimmerman JM, Maren S (2010) NMDA receptor antagonism in the basolateral but not central amygdala blocks the extinction of Pavlovian fear conditioning in rats. Eur J Neurosci 31:1664-1670. CrossRef Medline

Zimmermann T, Bartsch JC, Beer A, Lomazzo E, Guggenhuber S, Lange MD, Bindila L, Pape HC, Lutz B (2018) Impaired anandamide/palmitoylethanolamide signaling in hippocampal glutamatergic neurons alters synaptic plasticity, learning, and emotional responses. Neuropsychopharmacology. Advance online publication. Retrieved November 15, 2018. doi: 10.1038/ s41386-018-0274-7 